\title{
The Impact of Fiscal Austerity on Suicide Mortality: Evidence across the 'Eurozone Periphery'
}

\author{
Nikolaos Antonakakis*1,2,3 and Alan Collins ${ }^{2}$ \\ ${ }^{1}$ Vienna University of Economics and Business, Department of Economics, Institute for International \\ Economics, Welthandelsplatz 1, 1020, Vienna, Austria \\ ${ }^{2}$ University of Portsmouth, Economics and Finance Subject Group, Portsmouth Business School, \\ Portland Street, Portsmouth, PO1 3DE, United Kingdom \\ ${ }^{3}$ Webster Vienna Private University, Department of Business and Management, Praterstrasse 23, 1020,
} Vienna, Austria

November 20, 2015

\begin{abstract}
While linkages between some macroeconomic phenomena and suicides in some countries have been explored, only two studies, hitherto, have established a causal relationship between fiscal austerity and suicide, albeit in a single country. The aim of this study is to provide the first systematic multiple-country evidence of a causal relationship of fiscal austerity on time-, gender-, and age-specific suicide mortality across five Eurozone peripheral countries, namely Greece, Ireland, Italy, Portugal and Spain over the period 1968-2012, while controlling for various socioeconomic differences. The impact of fiscal adjustments is found to be gender, age- and time-specific. Specifically, fiscal austerity has short-, medium- and long-run suicide increasing effects on the male population in the 65-89 age group. A 1\% reduction in government spending is associated with an $1.38 \%, 2.42 \%$ and $3.32 \%$ increase in the short, medium- and long-run, respectively, of male suicides rates in the 65-89 age group in the Eurozone periphery. These results are highly robust to alternative measures of fiscal austerity. Improved labour market institutions help mitigate the negative effects of fiscal austerity on suicide mortality.
\end{abstract}

Keywords: Eurozone periphery, Fiscal austerity, Suicide, Government policy, Labour market institutions, Panel data

JEL codes: C33, H30, H51, H55, H62, I18, I31, J18

${ }^{*}$ Corresponding author: e-mail: nikolaos.antonakakis@port.ac.uk, phone: +44 (0)23 92844261. 


\section{Introduction}

Although fiscal austerity is widely discussed in the economic literature, much less has been published in terms of empirical evidence documenting its impact on suicide mortality. Some headway in filling this gap has been made in recent years, with studies focusing on descriptive or correlation analyses (see, for instance, Kentikelenis et al., 2011; Economou et al., 2011; Kentikelenis et al., 2012; Fountoulakis et al., 2012; Karanikolos et al., 2013) and on single country time series (Antonakakis and Collins, 2014; Branas et al., 2015). In this study, we report the first systematic multiple-country evidence of a relationship between fiscal austerity and suicide mortality, basing our analysis on a Eurozone periphery panel dataset, thereby covering a large share of countries that have recently implemented fiscal austerity in an attempt to restore confidence, competitiveness, and macroeconomic stability.

According to Lawson et al. (2014), the key drivers of population health lie outside the health sector. Despite that, the authors argue that, decision makers outside the health sector seem primarily interested in delivering sector specific outputs other than health. Thus, economic approaches to priority setting can help align sectors to consider the intersectoral impacts of decisions within an integrated societal framework.

Following the global financial crisis of 2008, many European countries, especially in the Eurozone periphery, experienced an increase in their budget deficits and government debts in late 2009. That raised fears about a chain reaction of sovereign defaults on the Eurozone peripheral countries' debt, and possible contagion to other core Eurozone countries. This led to a crisis of confidence and a widening of bond yield spreads and credit default swaps between the Eurozone peripheral countries and the Eurozone's largest economy, Germany. These developments have ultimately initiated a European sovereign debt crisis that has resulted in large financial interventions by individual governments and the 'Troika' (consisting of the European Commission (EC), 
the European Central Bank (ECB) and the International Monetary Fund (IMF)) in the Eurozone peripheral countries. These policy interventions occurred in an attempt to avert potential bankruptcies of highly indebted countries in the Eurozone periphery, potential contagion and ultimately the collapse of the Eurozone itself. In particular, fiscal austerity packages consisted of bailout packages to Eurozone peripheral countries that were accompanied by draconian and unprecedented fiscal adjustment measures. These consisted of large spending cuts, tax hikes, large privatisation schemes of publicly owned assets (with often largely overoptimistic initial sale values) and structural reforms, so as to restore competitiveness, achieve fiscal sustainability and promote growth.

Eventually, as business cycle theory suggests, every crisis comes to an end, and a 'good' policy is marked by its success in making the downturn of the business cycle shallower and shorter than it otherwise would have been. The controversy associated with austerity policies that many governments adopted relates to whether they made the downturn far deeper and longer than was necessary, with long-lasting consequences not only for wealth, but also for health. Thus a natural and important question is whether fiscal austerity will hurt economic performance and health conditions over time.

In terms of the economic consequences, conventional wisdom suggests that reduction of debt into sustainable levels has long-run benefits. For a recent detailed discussion of the macroeconomic effects of fiscal policy, see Afonso and Sousa (2012). However, there is no consensus reached yet on the short-run, or even the medium-run effects of fiscal consolidation/austerity. Keynesian economists might suggest that spending cuts and tax hikes will reduce economic activity in the short-run (see, for instance, Blanchard and Perotti, 2002). On the other hand, some economists argue that fiscal consolidation/austerity may be expansionary even in the short-run, which is referred to as "expansionary fiscal contraction" (see, for instance, Giavazzi and Pagano, 1990; Alesina and Perotti, 1995; Giavazzi and Pagano, 1996; Giudice et al., 2004; Afonso, 2010; 
Alesina and Ardagna, 2010; Alesina, 2010). The success or failure of fiscal consolidation depends on many factors, among which, its reliability on tax hikes primarily, the perceived risk of sovereign default, the number of countries that simultaneously apply such measures, and whether monetary policy is in position to offset budget cuts. For a discussion of these factors, see IMF (2010). Quite recently, the fairness of fiscal consolidation has entered the pool of these factors (Kaplanoglou et al., 2014).

Increasingly, the pursuit of fiscal austerity is being recognized by some as ineffective and prolonging the economic crisis unnecessarily (IMF, 2013). This is because any reduction in the fiscal deficit hurts the economy -at least in the short- to medium-term--, as it denotes that the government sector has a less positive contribution to the economy, which is compounded when the government is running a deficit. In light of Figure 1, the Eurozone debt crisis and the subsequent fiscal austerity may be considered to have led to a dramatic increase in government debts and deficits, deep recessions and skyrocketing unemployment rates in the Eurozone periphery since 2009. In particular, between 2009 and 2013, unemployment rates in Greece, Ireland, Italy, Portugal and Spain increased by $186.5 \%$ (from $9.6 \%$ to $27.5 \%$ ), $9.2 \%$ (from $12 \%$ to $13.1 \%$ ), $56.4 \%$ (from $7.8 \%$ to $12.2 \%$ ), $54.7 \%$ (from $10.6 \%$ to $16.4 \%$ ) and $45.8 \%$ (from $17.9 \%$ to $26.1 \%$ ), respectively. Youth unemployment in the respective countries over that period increased by $126.8 \%$ (from $25.7 \%$ to $58.3 \%$ ), $11.7 \%$ (from $24.7 \%$ to $26.8 \%$ ), $57.5 \%$ (from $25.4 \%$ to $40 \%$ ), $51.8 \%$ (from $25.1 \%$ to $38.1 \%$ ) and $47.2 \%$ (from $37.7 \%$ to $55.5 \%$ ). These figures are well above the Eurozone average increase of $26.3 \%$ (from $9.5 \%$ to $12 \%$ ) and $18.8 \%$ (from $20.2 \%$ to $24 \%$ ) in overall unemployment rates and youth unemployment rates, respectively. There is a well established link between unemployment and suicide, which tends to increase during economic downturns, particularly where it is not offset by welfare safety nets. For a more comprehensive list of suicide mortality determinants, see Chen et al. (2012). Moreover, the literature suggests that periods of high unemployment rates are positively associated with incidence rates of ab- 
sence due to symptoms of illness and violent acts (see, e.g., Shoss and Penney, 2012). According to the International Labour Organization (ILO), labour market conditions in the Eurozone have worsened (and are projected to continue to this course) due to fiscal austerity, constituting to the increase of unemployment rates (ILO, 2014) in the EU. In particular, the study of ILO (2014), argues that the current fiscal austerity measures and the cuts in government spending have heavily affected the funds available for social programmes for the most vulnerable groups of women. In 2013, 45.2 million people where unemployed in the EU and it was forecasted that the unemployment rate will gradually decline from $8.6 \%$ to $8 \%$ between 2013 and 2018 , albeit, significantly above that in 2008 (ILO, 2014). Real GDP per capita between 2009 and 2013 has seen a cumulative decline of $22.3 \%$ in Greece, $0.74 \%$ in Ireland, $3.11 \%$ in Italy, $2.84 \%$ in Portugal, and $2.92 \%$ in Spain as compared to the cumulative increase of $0.94 \%$ in the whole Eurozone according to Figure 1. Finally, government debt as a percentage of GDP between the same period increased by $35.0 \%$ (from $129.7 \%$ to $157.1 \%$ ), $92.1 \%$ (from $64.4 \%$ to $123.7 \%$ ), $13.9 \%$ (from $116.4 \%$ to $132.6 \%$ ), $54.1 \%$ (from $83.7 \%$ to $129 \%$ ) and $73.9 \%$ (from $54 \%$ to $93.9 \%$ ), in Greece, Ireland, Italy, Portugal and Spain, respectively, well above the Eurozone average government debt to GDP of $92.6 \%$ in 2013.

\section{[Insert Figure 1 around here]}

The effects of the economic crisis and the fiscal adjustments have to some limited extent been considered for health in the Eurozone periphery. Preliminary evidence indicates that the economic crisis and the implementation of austerity measures have worsened self-rated health status as well as several other health indicators (Kentikelenis et al., 2011; Vandoros et al., 2013; Zavras et al., 2013), increased the incident of mental disorders and alcohol abuse (Kentikelenis et al., 2011; Gili et al., 2013; Roca et al., 2013) and led to HIV outbreaks (ECDC, 2012). Evidence also suggests that the Eurozone debt crisis and the policy responses disproportionately 
affected vulnerable populations in society (see, e.g., Schaltegger and Weder, 2014, for the effects of fiscal consolidation on income inequality). Despite countries' attempts to make savings by switching to generic drugs, the policies that have been implemented to shift costs from the state to patients resulted in medicines growing less affordable and increasingly hard to access (Arie, 2013). Data, however, also suggest favourable health trends and a reduction of traffic deaths fatalities in the general population during recessions (Stuckler et al., 2009). This is in line with the literature that finds that work-related, and other types accidents (e.g. due to drinking and driving behaviours) are likely to become more common during temporary expansions of economic activity (see, for instance, Evans and Graham, 1988; Ruhm, 1995). Dolan et al. (2014), however, finds that road traffic accidents increased substantially in Greece on the first two days following the announcements of austerity measures. Moreover, egalitarian policies protecting the most disadvantaged populations with strong social protection have proved to be effective in decoupling the link between job losses and suicides (De Vogli, 2014).

Yet, the health effects of fiscal austerity have been shown to have not been assessed consistently (see, for instance, Webb and Kapur, 2015). Empirically robust evidence on the link between fiscal austerity and suicide mortality has only been establish in Greece by Antonakakis and Collins (2014) and Branas et al. (2015), or via descriptive and/or correlation analyses in Greece and other Eurozone peripheral countries (see, for instance, Kentikelenis et al., 2011; Economou et al., 2011; Kentikelenis et al., 2012; Fountoulakis et al., 2012; Karanikolos et al., 2013).

To address this gap in the literature, we specifically investigate the effects of fiscal austerity, among other socio-economic control variables, on suicide rates in all Eurozone peripheral countries, namely, Greece, Ireland, Italy, Portugal and Spain over the period 1968-2012. Our empirical findings suggest that fiscal austerity, higher unemployment rates, negative economic growth and reduced fertility rates lead to signicant increases on overall suicide rates in the Eu- 
rozone periphery. The effects of fiscal austerity are gender, age and time specific, with fiscal austerity having short-, medium- and long-run suicide-increasing effects on the male population between 65 and 89 years of age. In particular, a 1\% reduction in government spending leads to an $1.38 \%, 2.42 \%$ and $3.32 \%$ increase in the short-, medium- and long-run, respectively, of male suicides rates between 65 and 89 years of age in the Eurozone periphery. In addition, unemployment benefits and substantial employment protection legislation can help mitigate the negative effects of fiscal austerity on suicide mortality.

These results have potentially important implications for policy makers across Europe. Economic and financial issues have been dominating policy making in the Eurozone, while health and inequalities in health have arguably remained relatively low key. Given that economic and social policy decisions have profound effects for health and its fair distribution, health equity should perhaps be considered an important measure of the effectiveness of social and economic policy making, in addition to wealth equity (see, for instance, Marmot, 2012).

The remainder of this paper is organised as follows. Section 2 presents some brief remarks on the extant theory relating to suicide, outlines the sources of our theoretical expectations and sets out our key research hypotheses. Section 3, specifies the empirical methodology and the data used. Section 4 presents the empirical results and Section 5 summarises and offers some concluding remarks.

\section{$2 \quad$ Key Hypotheses}

Numerous studies have explored the impact of various macroeconomic phenomena on reported subjective wellbeing (Di Tella et al., 2001, 2003; Alesina et al., 2004) typically presenting intuitively plausible results. Suicide, however, serves as a very clear revealed objective measure of substantial life dissatisfaction and as a potential indicator of wider mental health issues and wellbeing issues in a given economy. It has long been the subject of theoretical and empirical 
scrutiny. Durkheim (1897) and other sociologists in their wake have posited a positive relationship between suicide and age premised on the level of both social integration and social regulation in a given society. Economists too have entered the arena led by Hamermesh and Soss (1974) who advanced a rationality driven model of suicide founded on an assessment of the likely expected cumulative lifetime utility.

Hamermesh and Soss (1974) posit a positive relationship between suicide rates and age, and an inverse relationship with permanent income which can be expected to boost expected cumulative lifetime satisfaction. The authors have empirically presented that these predictions hold over time and across US states. Based on the extensive and very comprehensive review of studies presented in Chen et al. (2012), this study extracts a full set of a priori expectations for the macroeconomic performance and socio-demographic control variables based on the consensus readily discernible in the literature. For a comprehensive list of suicide determinants see Chen et al. (2012). These are set out in Table 1. However, in the context of fiscal austerity (specifically public expenditure reductions) we posit the following hypotheses:

Hypothesis 1: Fiscal austerity will increase suicide rates, via permanent income reductions.

Hypothesis 2: Fiscal austerity impacts significantly differently across age cohorts. Specifically, older age cohorts are more likely to commit suicide as a consequence of fiscal austerity than younger age cohorts, given reliance on fixed incomes.

Hypothesis 3: Fiscal austerity effects on suicide rates have both contemporaneous and lagged effects.

Hypothesis 4: Fiscal austerity effects on suicide rates are dampened by better labour market institutions (e.g. unemployment benefits and employment protection legislation). 


\section{Data and Methodology}

\subsection{Data}

To conduct our analysis, we collect annual observations of suicide statistics for Greece, Ireland, Italy, Portugal and Spain between 1968 and 2012. Suicide data (defined as number of deaths by suicide and self-inflicted injury/intentional self-harm, based on the following international classification of diseases (ICD) codes, ICD-7 codes E963 and E970-E979, ICD-8 and ICD-9 codes E950-E959, ICD-10 codes X60-X84) and population data are extracted from the World Health Organization (WHO) Mortality Database and are extended up to 2012 with data on suicide and population supplemented from the official national statistics of each country and Eurostat, respectively. A snapshot of these series is presented in Panel A of Table A.2 in the Appendix.

Based on the above data, we convert the number of suicides to suicide rates per 100,000 inhabitants, broken down by age and gender in each country using the WHO standard procedure (e.g., see Ahmad et al., 2012). Selected years for these series reported in Panel B of Table A.2 in the Appendix, reveal similar trends as those for the number of suicides in Panel A of the same table. The evolution of unemployment rates together with suicide rates, which is presented in Figure 2, is quite revealing. It indicates that suicide mortality is gender and country specific, indicating the necessity to take into account the gender heteogeneity and control for countryspecific effects in the empirical analysis.

[Insert Figure 2 around here]

In Figure 3 which plots the Eurozone 5 peripheral countries' average suicide rates by age group and gender, reinforces the aforementioned age and gender heterogeneity. Nevertheless, it is also depicts a positive trend of suicide rates overtime, which is more pronounced in the male 
population. This indicates the necessity to control for Eurozone periphery-wide time-effects in the analysis.

[Insert Figure 3 around here]

In order to examine the effects of fiscal austerity on suicide rates, we use several variables as proxies of fiscal austerity. Given the large scale reductions in public sector salaries and pensions in the Eurozone peripheral countries, our principal proxy of fiscal austerity is government expenditure. We collect data for general government final consumption expenditure as a \% of GDP from the World Bank World Development Indicators (WDI) database. Given that this measure might produce biased results during period when nominal GDP is falling, such as the period of the financial crisis, we have explored the robustness of our results by dividing general government final consumption expenditure by real GDP or by population. Our results, which are available upon request, remain qualitatively and quantitatively almost identical. This is due to the fact that the correlation between the three alternative measures is very high, namely 0.7521 and 0.7465 , respectively. For robustness purposes we also use a fiscal consolidation episodes indicator (FCE) based on Afonso (2010), the budget deficit, taxes, and government spending on public health as proxies of fiscal austerity (see below). In addition, we collect data on per capita real GDP growth from WDI so as to examine the cyclical nature of suicide mortality. Finally, to control for social and demographic factors on suicide rates and to minimize errors arising from unobserved effects, we collect data for fertility rates from the World Bank World Development Indicators (WDI) database and Eurostat; alcohol consumption from OECD Health database and divorce rates from EUROSTAT. Our panel dataset is unbalanced (please see Table A.1 for data availability. Definitions, expected signs and descriptive statistics for all these variables are included in Table 1.

[Insert Table 1 around here] 
In Figure 4 we present the evolution of some of the macroeconomic series over the period 1968-2012 that are used in this study. According to this figure, economic growth, budget deficit and public debt deteriorated since 2009, while government expenditure was severely cut since 2009 in the Eurozone periphery.

[Insert Figure 4 around here]

\subsection{Empirical Methodology}

We estimate variants of the following specification:

$$
S_{i j k t}=\alpha+S_{i j k t-1} \beta_{1}+F_{i t} \beta_{2}+F_{i t-1} \beta_{3}+E_{i t} \boldsymbol{\lambda}+D_{i t} \boldsymbol{\mu}+\gamma_{i}+\delta_{t}+\varepsilon_{i t}
$$

where $S_{i j k t}$ is the $\log$ of suicide rates in country $i$ (where $i=$ Greece, Ireland, Italy, Portugal, Spain), population $j$ (where $j=$ overall, male, female), age group $k$ (where $k=$ all, 10-24, $25-44,45-64,65-89$ ) and time $t$ (where $t=1968, \ldots, 2012$ ); $\alpha$ is a constant; $S_{i j k t-1}$ is the first lag of $S_{i j k t}$ and is included to account for dynamic effects and to filter autocorrelation of order one, $\operatorname{AR}(1)$, found in the series. Given that the lagged dependent variable, $S_{i j k t-1}$, is correlated with the fixed effects, this gives rise to 'dynamic panel bias' (Nickell, 1981), which inflates the coefficient of the lagged dependent variable by attributing predictive power to it that actually belongs to the country's fixed effect. According to Judson and Owen (1999) the so-called least-squares dummy-variables (LSDV) estimator bias is present for panels with small time, $T$, dimension. A potential solution to this bias (and to potential endogeneity of other right-hand side variables), is to use a generalised method of moments (GMM) approach, e.g. systemGMM. However, this approach is designed for small time, $T$, dimension and large individual, $N$, dimension panels (for a discussion, see Roodman, 2009). An even more appropriate solution to the aforementioned bias is to use the bias-corrected least-squares dummy variable (BCLSDV) estimator of Bruno (2005a,b) that is suitable for dynamic unbalanced panels. Given the fact 
that: i) our panel is unbalanced and consists of large $T(\approx 44)$ and small $N(=5)$, and ii) as Bruno (2005a,b) show that, based on Monte Carlo analysis, the BCLSDV estimator performs better than the original LSDV estimator and three popular N-consistent estimators: Arellano-Bond, Anderson-Hsiao and Blundell-Bond when the panel is unbalnced, we thus employ the BCLSDV estimator. However, all of our results using the LSDV estimator (that are presented in the paper) are similar to those obtained using the (one-step or two-step) system-GMM estimator (that is robust to substantial heteroskedasticity) derived by Arellano and Bond (1991), and further developed by Blundell and Bond (1998) and Arellano and Bover (1995). Moreover, our results are very robust to alternative estimators that account for first-order autoregressive, heteroscedastic and/or autocorrelated disturbances. The latter results are available upon request. $E_{i t}$ is a vector of economic characteristics affecting suicide rates, such as the growth rate of real GDP, Growth $h_{i t}$, and the unemployment rate, $U n e m p_{i t} ; F_{i t}$ is the fiscal consolidation variable proxied by either: (i) the first difference of the natural logarithm of government expenditure as a \% of GDP, Gov_Exp ${ }_{i t}$, or (ii) the first difference of budget deficit as a \% of GDP, Def $f_{i t}$, or (iii) government tax revenues as a \% of GDP, $\operatorname{Tax}_{i t}$, or iv) fiscal consolidation episodes (FCE) indicator based on Afonso (2010), or v) real per capita government spending on public health Pub_Health_Exp ${ }_{i t}$. We also include a one period lag of the fiscal consolidation/austerity variable, $F_{i t-1}$, so as to control for any time delayed effects of fiscal consolidation/austerity on suicide mortality. $D_{i t}$ is a vector of demographic and social characteristics affecting suicide rates, such as alcohol consumption, $A l c_{i t}$, divorce rate, Divorce $i t$ and fertility rate, Fert $t_{i t} \cdot \gamma_{i}$ denotes country fixedeffects controlling for time-invariant country characteristics, and $\delta_{t}$ denotes time fixed-effects, controlling for Eurozone periphery country-invariant time characteristics. The fixed-effects estimates are used to exploit within-country variations in economic conditions and have the potential to improve on time series analyses if there are substantial independent socio-economic fluctuations across countries over time. $\varepsilon_{i t}$ is the error term. 
The intuition for incorporating the range of right-hand side variables deployed in this study follows the consensus evident in the recent literature surveyed by Chen et al. (2012). Andrés (2005) and Viren (2005) establish a significant linkage between economic growth and suicide. Given positive economic growth enhances occupational and financial opportunities, people are more likely to be hopeful decreasing the probability of suicide. In a similar vein, unemployment serves as a predictor of future income and thus rising unemployment should be expected to lead to an increasing incidence of suicide and suicide attempts. Further, suicide may also be associated with a range of mental and physical illnesses that may raise the probability of suicidal behaviour.

In the seminal work of Durkheim (1897) suicide mortality was postulated to be strongly influenced by social regulations and its degree of integration. Arguably, divorce and fertility rates may be presented as indicators of social integration. Durkheim specifically highlights divorce as serving to reduce social integration and family ties resulting in stress, shame and a greater disposition towards suicidality. Accordingly, higher divorce rates tends to be related to higher suicide rates (see, for example Minoiu and Andres, 2008; Brainerd, 2001; Neumayer, 2003, among others).

Durkheim (1897) and Andrés (2005) make the case for fertility rate to be viewed as an indicator of social integration, suggesting high fertility rates are related to lower suicidality. The absence of children is thus associated by them with greater fluidity in family integration and social ties. Finally, Neumayer (2003) and Andrés (2005) find that, individuals with a higher alcohol consumption are more likely to commit suicide. 


\section{Estimation Results}

\subsection{Baseline Results: Short-run Effects}

In Tables 2, 3 and 4 we report the main results with particular focus onto the short-run effects of fiscal austerity on the overall, male and female population, respectively, in the Eurozone periphery.

[Insert Table 2 around here]

[Insert Table 3 around here]

[Insert Table 4 around here]

Turning to the results of Table 2, we observe that suicide rates are very persistent as the coefficient of the one year lagged dependent variable has a statistically significant positive effect on current suicide rates. Downturns of economic activity increase suicide rates across all ages. This result is in line with Breuer (2014). For instance, one percentage point decline in a Eurozone periphery country's growth rate of real GDP per capita increases suicide rates of the population across all ages by $0.9 \%$, and of the population between 10 and 44 , and 65 and 89 years of age by around $1.3 \%$. Moreover, the results of Table 2 suggest that increases in unemployment leads to significant increases in overall suicides rates of $10-24$ years of age, with a 1 percentage point increase in a Eurozone periphery country's unemployment rate leading to a $1.48 \%$ increase in suicide rates in that age group. These results are in line with Breuer (2014) and Ruhm (2000). Breuer (2014) finds that, for European regions, a 1 percentage point increase in a European region's unemployment rate is predicted to increase suicide rates of working age population by about $0.87 \%$, while the latter authors find that for the U.S., a 1 percentage point increase in a state's unemployment rate is predicted to increase overall suicide rates by about $1.3 \%$. Our results are also quite similar to Stuckler et al. (2009) who find that, for 26 European countries, 
a 1 percentage point increase in unemployment is associated with a $0.79 \%$ rise in suicide at ages younger than 65 years. Unemployment is the leading cause of youth suicides in the Eurozone periphery, and as youth unemployment has deteriorated substantially in the eurozone periphery (see Figure 1), this is an alarming figure. Fertility rates are negatively related to suicide rates, especially in the overall population between the ages of 10 and 24, 25 and 44, and 65 and 89 in the Eurozone periphery.

Turning our attention to the impact of fiscal austerity on suicide rates, we find that, fiscal austerity is also a significant predictor of suicide mortality, having both significant contemporaneous and lagged effects on suicide rates across various age groups. In particular, reductions in government spending lead to contemporaneous increases in suicides rates in the population group of 45-64 and, especially, in the 65-89 group, while with one year lag increases in suicide rates in the population groups of 10-24, 25-44 and $65-89$. For instance, for each $1 \%$ reduction in a Eurozone periphery country's government spending, the suicide rate of the population between 65 and 89 is predicted to rise by about $1.00 \%(-0.64 \%$ plus $-0.36 \%)$ in the short-run. This seems plausible, since the oldest age groups are naturally likely to be more inflexible following implementation of any fiscal austerity that would reduce their incomes (especially from pensions). Younger segments of the population affected by fiscal austerity measures have a wider range of perceived opportunities beyond suicide. Finally, alcohol consumption or divorce rates do not exert any significant influence on suicide mortality in the overall population and across all ages in the Eurozone periphery.

Moving to the results for the male population reported in Table 3, it may be observed that they are similar to those for the overall population. In particular, government spending cuts, negative economic growth, reduced fertility rates and, to a lesser extent, increased unemployment, have a significantly positive impact on male suicide rates. The male population group that is most heavily affected by spending cuts is the one between the 65 and 89 years of age. In this 
group, a $1 \%$ reduction in a Eurozone periphery country's government spending is significantly associated with a contemporaneous and a year lag increase of $0.80 \%$ and $0.58 \%$, respectively, in male suicide rates. That is, for every $1 \%$ reduction in a Eurozone periphery country's government spending, the suicide rate of the male population between 65 and 89 is predicted to rise by about $1.38 \%(=-0.80 \%$ plus $-0.58 \%$; column (10) of Table 3$)$. Put differently, the shortrun impact or 'health' multiplier of fiscal austerity on male suicides in the 65-89 year group is $-1.38 \%$. To put things into perspective, final consumption expenditure as a percentage of GDP in the Eurozone periphery declined on average by $4.486 \%$ in $t=2011$ (from 2010 to 2011 ) and by $4.137 \%$ percentage in $t-1=2010$ (from 2009 to 2010$)$, resulting in a $11.901 \%(=8.624 \% \times 1.38 \%$ ) increase in male suicide rates between 65 and 89 years in the Eurozone periphery on average in 2011. Given that the Eurozone periphery average male population in the $65-89$ group in 2011 was $2,064,061$, the $11.901 \%$ increase corresponds to 246 suicides in every Eurozone periphery country on average in 2011 solely due to fiscal austerity. Following this approach, the number of males in the 65-89 age group who committed suicide solely due to fiscal austerity in 2012 amounted to 219. Put differently, between 2011 and 2012, 465 males in the 65-89 age group committed suicide in every Eurozone periphery country on average due to, ceteris paribus, fiscal austerity; or $54.07 \%(=(465 /(456+404) \times 100))$ of all the suicides recorded in every Eurozone periphery country on average in 2011 and 2012, was due to fiscal consolidation/austerity. In other words, $2325(=5 \times 465)$ males in the $65-89$ age group committed suicide in the whole Eurozone periphery between 2011 and 2012 due to fiscal austerity measures.

In contrast, fiscal austerity does not seem to have had any significant contemporaneous impact on female suicide rates. However, there are suicide-increasing effects for female in the 25-44 age group with a year lag of the implementation of austerity. For every $1 \%$ reduction in a Eurozone periphery country's government spending, the suicide rate of the female population between the ages of 25 and 44 is predicted to rise by $0.72 \%$. The females in all the other age 
groups seem to be resilient to fiscal austerity. Fertility rates, divorce rates and alcohol consumption are also significant predictors of female suicides. In particular, increases in fertility rates (alcohol consumption) have significant suicide-reducing effects among the female population between the ages of 45 and 89 (between the ages of 10 and 24, and 65 and 89), while increases in divorce rates lead to a significant increase of female suicide rates between the ages of 45 and 89 years of age.

Overall, these results suggest that suicides rates in the Eurozone periphery are of a persistent nature, and that the effects of economic growth, unemployment, spending cuts, fertility rates, divorce rates and alcohol consumption on suicide mortality are age and gender specific. More importantly, these results suggest that economic policies, such as fiscal austerity, can also have an impact on suicide mortality, and potentially offer some guidance on the demographic targeting of suicide prevention measures for the population of the debt-stricken economies in the Eurozone periphery.

\subsection{Medium- and Long-run Effects}

So far, fiscal austerity has been assumed to have only a contemporaneous and a year lag effect, i.e. short-run impact, on suicide mortality. In order to provide information on the potential medium- and long-run effects of the fiscal adjustment process on suicide mortality, we: i) reestimate model (1) with the inclusion of five year lags of fiscal austerity as:

$$
S_{i j k t}=\alpha+S_{i j k t-1} \beta_{1}+F_{i t} \beta_{2}+F_{i t-1} \beta_{3}+\ldots+F_{i t-5} \beta_{7}+E_{i t} \boldsymbol{\lambda}+D_{i t} \boldsymbol{\mu}+\gamma_{i}+\delta_{t}+\varepsilon_{i t}
$$

and use the resulting estimates to summarize the predicted impact of a sustained $1 \%$ decline in government expenditure that begins in year $t$ and continues through $t+5$, in similar fashion as in Ruhm (2000) (The choice of a five-year lag is based upon the fact that: a) the coefficient of the sixth lag in the overall, male and female suicide mortality equation has a $p$-value greater than 0.10 , and b) given that fiscal austerity, at the time of the writing of this study, is pursued 
for the 5th consecutive year, it seems warranted to assess its medium term impact on suicide mortality), and ii) calculate the long-run multiplier of fiscal austerity on suicide based on the following equation:

$$
\beta_{L R}=\frac{\hat{\beta}_{2}+\hat{\beta}_{3}}{1-\hat{\beta}_{1}}
$$

where $\hat{\beta}_{1}$ denotes the estimated parameter of the lagged suicide rates from model 1 , and $\hat{\beta}_{2}$ and $\hat{\beta}_{3}$ the estimated parameters of the contemporaneous and lagged fiscal austerity variables, respectively, from model 1.

The results of the medium-run effects of fiscal austerity on suicides rates are reported in Table 5, while the cumulative adjustment path of suicide rates is presented in Figure 5.

[Insert Table 5 around here]

[Insert Figure 5 around here]

According to Table 5 and Figure 5, we observe that, although that the time profile varies with age and gender, a sustained cut in government spending is strongly associated with both short-run and medium-run increases in suicide rates in the Eurozone periphery, lasting up to five years following the application of fiscal austerity. However, this varies across gender and age. In particular, persistent cuts in government spending significantly increase suicide rates of males across all ages in the medium-run, while no significant medium-run effects on the female population could be identified in the Eurozone periphery. The latter group seems to be resilient to sustained budget cuts in the medium run, as only contemporaneous, one and two year lag effects of budget cuts have a significant positive impact on female suicide mortality in the 65-89, 25-44 and 45-65 age groups, respectively, in the Eurozone periphery.

The age group most heavily affected by sustained budget cuts is the male population in the 65-89 age group, followed be males in the 25-44 age group. For instance, the expected bottom-line 
(medium-run) effect of a sustained 1\% decline in a Eurozone periphery's government spending, according to Figure 5, is an increase of $2.42 \%(=0.89 \%+0.75 \%+0.78 \%)$ in the suicide rates of males in the 65-89 age group. Given that final consumption expenditure as a percentage of GDP in the Eurozone periphery on average declined on average by $15.401 \%$ (which is derived as the sum of the $4.137 \%, 4.486 \%$ and $3.102 \%$ decline in government spending as a $\%$ of GDP between 2009 and 2010, 2010 and 2011, and 2011 and 2012, respectively, and (based on updated data on government spending as a $\%$ of GDP from the AMECO database) $0.179 \%$ increase in government spending as a \% of GDP between 2012 and 2013, and 3.854\% decline in government spending as a \% of GDP between 2013 and 2014.) from 2009 to 2014 (i.e. in 5 years), the medium-run effects of fiscal austerity translate to a $37.27 \%(=15.401 \% \times 2.42 \%)$ increase in male suicide rates in every Eurozone periphery country on average due to sustained fiscal austerity. Based on data for population projections from Eurostat (code: proj_13npms), the male population of 65-89 years in the Eurozone periphery on average is projected to be $2,444,577$ in 2014, resulting in 911 predicted male suicides in every Eurozone periphery country on average due to sustained fiscal austerity between 2009 and 2014. Put differently, 4556 male suicides between the ages of 65 and 89 are predicted to have been committed in the whole Eurozone periphery between 2009 and 2014 due to sustained fiscal austerity.

Apart from the short-run (impact multiplier) and the medium-run effects of fiscal austerity on suicide rates obtained above, we can also compute the long-run multiplier of fiscal austerity on suicides rates based on equation (3). This stems from the fact that results of fiscal austerity and their associated repercussions could have long-lasting impacts on the mental health of the most deprived sections of the population in the Eurozone periphery. According to Table 6, the long-run multiplier of fiscal austerity on overall and male suicide rates of the population between 65 and 89 years of age is $-2.61 \%(=(-0.0064-0.0036) /(1-0.6172))$ and $-3.32 \%(=$ $(-0.0080-0.0058) /(1-0.5849))$, respectively. That is, for every $1 \%$ cut in a Eurozone periphery's 
government spending, the suicide rates of the male population between the 65 and 89 years of age is predicted to rise by $3.32 \%$. To put things into perspective, final consumption expenditure as a percentage of GDP in a Eurozone periphery country on average declined by $8.624 \%(4.137 \%$ in $t-1=2010$ and $4.486 \%$ in $t=2011)$, resulting in a $28.63 \%(=8.624 \% \times 3.32 \%)$ long-run increase in male suicide rates in the 65-89 age group because of fiscal austerity. Again, based on population projections from Eurostat (code: $\operatorname{proj}_{-} 13 n \mathrm{nms}$ ), the male population of 65-89 years in the Eurozone periphery on average is projected to be 2,355,280 in 2020 (2020 is considered as the benchmark long-run run scenario, based on the fact that the Greek government is bound to the Troika's bailout scheme and the corresponding structural adjustments, at least, till 2020), resulting in a 674 elderly male suicides in the long-run in every Eurozone periphery country on average, or in 3370 elderly male suicides in the whole Eurozone periphery in the long run as a result of fiscal austerity. This might, at first glance, seem contradictory to earlier results. However, it can be readily explained by the fact that, in the long run, people will be able to 'adjust' to the situation more efficiently (e.g. via migration, or, given the life expectancy of this age group, death, due to natural causes) compared to the short- or medium-run. In the short- or medium-run, resources and flexibility are limited, leaving little or no space to manoeuvre. Yet, the number of suicides associated with fiscal austerity is still very high, even in the long-run.

[Insert Table 6 around here]

Overall, these results suggest that the effects of fiscal austerity have long lasting effects on suicide rates of the aforementioned parts of the population in the Eurozone periphery.

\subsection{Robustness Analysis}

\subsubsection{Alternative Proxies of Fiscal Austerity}

In this section we examine the robustness of our results by using alternative proxies of fiscal austerity. In particular, we re-estimate model (1) four times, each of which with the following 
four alternative fiscal austerity proxies:

1. Budget deficit as a percentage of GDP. Specifically, we include the first difference of government budget deficit as a \% of GDP, Defit.

2. A fiscal consolidation episodes (FCE) indicator based on Afonso (2010) defined as:

$$
F C E_{i t}= \begin{cases}1, & \text { if } \Delta b_{i t}>\gamma \sigma, \\ 1, & \text { if } \sum_{k=0}^{1} \Delta b_{i t-k} / 2>\sigma, \\ 0, & \text { otherwise, }\end{cases}
$$

where $b$ is the primary structural budget balance in country $i$ and time $t$, and $\sigma$ is the standard deviation for the EU15 (specifically, $\sigma_{E U 15}=1.25$ ) while $\gamma$ is applied to determine a multiple of the standard deviation. Using the first difference of the primary structural budget balance as a $\%$ of GDP, $\Delta b_{i t}$, also known as fiscal impulse, it allows us to correct of the effects on budget balance from changes in economic activity such as inflation or real interest rates. Following Afonso (2010) we use $\gamma=1.5$. According to Afonso (2010), there is an element of arbitrariness with the choice of $\gamma$. In this particular case, $1.5 \sigma$ corresponds to 1.875 percentage points of GDP, thus indicating a more demanding threshold to determine a fiscal episode. Hence, a fiscal consolidation episode occurs when either the change in the primary cyclically adjusted balance is at least one and a half times the standard deviation in one year, or when the change in the primary cyclically adjusted balance is at least one standard deviation on average in the last 2 years.

3. Government tax revenues expressed as a percentage of GDP, Taxit.

4. Real government per capita expenditure on public health, Pub_Health_Exp $p_{i t}$.

The results of this analysis are presented in Tables A.4 - A.15 in the Appendix.

According to these results, reductions in budget deficits have a significantly positive and instantaneous impact on male suicides in the age group of $45-89$, while a significantly positive 
but with a year lag on female suicides in the 65-89 age group in the Eurozone periphery. Based on the fiscal consolidation episodes indicator as used in Afonso (2010), the results are quite similar. In particular, suicide rates of males in the oldest groups significantly and contemporaneously increase following a fiscal consolidation episode. These results are in line with our main findings, that fiscal consolidation mostly affects the elderly male population. Moreover, higher tax revenues by governments in the Eurozone periphery significantly increase suicide rates only of the male population between the ages of 25 and 44 within a year. There is also a negative and contemporaneous effect of higher tax revenues on male suicide mortality in the 25-44 age group. However, the overall short-run effect of a one percentage point increase in a Eurozone periphery's taxes is an increase in males suicide rates in the $25-44$ age group by $0.85 \%(=-1.48 \%+2.33 \%)$; see column $(6)$ in Table A.11. A potential explanation for this effect is that, the 25-44 male age group of the population consists of potential entrepreneurs who are thinking of starting a new (or already run a) business, but are strongly affected by their inability to pay taxes, leading to business closures, income losses, depression and, eventually, suicide. Finally, the coefficients of the remaining socio-economic determinants are in line with our main findings. For instance, higher divorce rates and lower fertility rates significantly increase suicide mortality mostly among both the male and female elderly population in the Eurozone periphery.

\subsubsection{The Role of Labour Market Institutions}

As a final robustness check, we explore whether labour market institutions have an influence on job satisfaction and the quality of life (for a discussion, see e.g. McKee-Ryan et al., 2005), and ultimately on suicide mortality. Breuer and Rottmann (2014) examine the effects of labour market institutions, among other socio-economic factors, on suicide mortality in a panel of 25 OECD (advanced) countries, and find that unemployment benefits decrease male suicides, while relatively strict employment protection regulations are positive related with suicide mortality of 
both genders.

Theoretically, this can occur in the following ways: (i) stricter labour market regulations and higher unemployment benefits could help mitigate the negative effects of income loss of workers in the case of unemployment during period of negative economic activity and (ii) they will be comparable to a social security system for employees in a private market, acting as safety nets in the risk of unemployment. For a detailed discussion on the potential channels, see Breuer and Rottmann (2014).

To conduct this final robustness check, and following Breuer and Rottmann (2014), we collect data for an indicator of employment protection legislation (EPL version EPRC_V1) from OECD database. The EPL (version EPRC_V1) indicator is defined as an indicator of the strictness of employment protection of regular workers against individual and collective dismissals, and can be retrieved from: http://tinyurl.com/qdf2zmu. This indicator is available between 1985 and 2013. There also exists another very closely related indicator of employment protection legislation developed by Allard (2005) over the period 1950-2003. In fact the correlation between the OECD EPL and the Allard (2005) indicators of employment protection legislation for the overlapping periods (1985-2003) in the Eurozone periphery is very high, namely 0.992. Thus, to increase the amount of observations and consequently predictive power of the results, we obtain the annual growth rate of the Allard (2005) indicator from 1985 to 1968, and apply it backwards to the OECD EPL indicator starting in 1984. Our indicator of unemployment benefit is proxied by the gross replacement rate (GRR), which is defined as gross unemployment benefit level as a percentage of previous gross earnings and obtained from OECD labour market statistics database. The series can be retrieved from www.oecd.org/els/soc/GRR_EN.xlsx. This indicator comes in two versions: (i) GRRAPW from 1961 to 2005 and (ii) GRRAW between 2001 and 2011. The former is calibrated to the average productive worker, while the latter is calibrated to average worker. Both indicators are available in uneven years. We fill missing values 
for both series by linear interpolation and extend the GRRAPW indicator with the growth rate of GRRAW from 2005 to 2011. Thus we end up with a combined indicator of unemployment benefits between 1968 and 2011.

In Tables 7 - 9 we present the results with the aforementioned indicators of labour market institutions. In particular, under columns (1), (3), (5), (7) and (9), we include the indicators for employment protection and for gross replacement rate, and under columns (2), (4), (6), (8) and (10), we also include their interaction with the fiscal austerity proxy so as to examine whether these interactions affect the results. According to the results under columns (1), (3), (5), (7) and (9), substantial employment protection legislation -especially that supporting older aged segments of the population- and higher unemployment benefits for the 25-44 (65-89) age groups of both sexes (males) have significantly suicide-reducing effects. The latter (former) result is partially in line (contrasts) with those in Breuer and Rottmann (2014). For instance, in the presence of improved labour market institutions and unemployment benefits, a one unit increase in a Eurozone periphery country's employment protection legislation indicator and gross replacement ratio (i.e. unemployment benefits) indicator is predicted to decrease male suicide rates in the age group of $65-89$ by $5.18 \%$ and by $0.33 \%$, respectively (see column (10) of Table 8), and thus help mitigate the negative effects of fiscal austerity on suicide mortality. In particular, given that the population of males in the age group of 65-89 in 2011 was, on average, 2,064,061 in the Eurozone periphery, 107 and 7 suicides could have been avoided in a Eurozone periphery country on average in 2011, due to more substantial employment protection legislation and improved unemployment benefits, respectively. This corresponds to $570(=535+35)$ suicides that could have been avoided in the whole Eurozone periphery in 2011 as a consequence of improved labour market institutions. However, in reality, the indicator of employment protection legislation and unemployment benefits declined by 0.1556 and 1.0101 units, respectively, in 2011 (compared to 2010), thus leading to an increase in male suicides between 65 and 89 years of age by $0.81 \%$ and 
$0.36 \%$, respectively. In other words, 17 and 7 male suicides in the 65-89 age group occurred in 2011 in every Eurozone periphery country on average, or, $85(=17 \times 5)$ and $40(=8 \times 5)$ male suicides in the 65-89 age group occurred in the whole Eurozone periphery, due to the deterioration of employment protection legislation and unemployment benefits, respectively. Finally, under columns (2), (4), (6), (8) and (10) in Tables 7 - 9, that present the results of the interaction of labour market institutions with fiscal austerity $\left(E P L * G o v \_E x p_{i t}\right.$ and $\left.G R R * G o v \_E x p_{i t}\right)$, we observe that only the interaction of fiscal austerity and employment protection legislation is positively and statistically significant only for males in the 65-89 age group, indicating that the observed decline in employment protection legislation combined with fiscal austerity led to a significant increase in suicide rates in that group. Interestingly enough, once the interaction is controlled for, the coefficients of fiscal austerity $\left(G o v_{-} E x p_{i t}\right.$ and Gov_Exp $\left.p_{i t-1}\right)$ become insignificant indicating that the detrimental effects of austerity on suicide mortality of males in the 65-89 age group in the Eurozone periphery could be mitigated with increased employment protection legislation.

[Insert Table 7 around here]

[Insert Table 8 around here]

[Insert Table 9 around here]

Summing up, these results suggest that the negative effects of economic downturns and fiscal austerity could be mitigated by the adoption of redistributive policies and by investing in some specific elements of stronger social protection in the Eurozone periphery; and are in line with Kaplanoglou et al. (2014) who find that, improving the targeting of social transfers and their effectiveness in terms of poverty alleviation, higher public expenditure on training and active labour market policies and programmes like social housing directed to the poor, even decreasing 
the VAT rate on necessities, improve the success probabilities of consolidation/austerity attempts. Overall, these results have also important implications for policy makers in the domain of economics and health across Europe. Economic and financial issues have been dominating policy making in the Eurozone, while health and inequalities in health remaining relatively low key in policy discussion. Given that economic and social policy decisions have profound effects on health and its fair distribution, health equity should be an important measure of the effectiveness of social and economic policy making, in addition to wealth equity (Marmot, 2012).

\section{$5 \quad$ Summary and Concluding Remarks}

The 2008 global financial crisis that subsequently transformed to a fully-fledged Eurozone sovereign debt in crisis in 2009, has clearly highlighted the health effects experienced by countries, such as the peripheral Eurozone countries, that have been heavily affected by soaring unemployment, financial distress and slumps in economic activity. Unprecedented policy interventions have been experienced in the peripheral debt-stricken Eurozone economies in an attempt to restore confidence, competitiveness, and macroeconomic stability.

However, the timing, scope, size and necessity of the policy responses, comprising mainly bank bailouts and austerity programmes, in most European countries still remains controversial, and has led to concerns about their economic and health effects. Not only crises, but also economic policy responses can lead to increased suicide mortality, widen inequalities in both wealth and health, and undermine the social fabric of the society. Clearly, the Eurozone debt crisis - especially in the peripheral Eurozone countries that have been heavily affected by the crisis and the policy responses - is not over, and it seems to be transforming into a health crisis. Prospects for economic and health recovery remain quite uncertain and fragile.

In this study, we explore the impact of fiscal austerity on suicide mortality across all Eurozone peripheral economies, while controlling for various economic and socio-demographic differences. 
Based on several proxies of fiscal austerity and robustness checks, the empirical regularities of this study reveal that the impact of fiscal adjustments is gender, age and time specific. In particular, fiscal austerity has short-, medium- and long-run suicide increasing effects on the male population between 65 and 89 years of age. A 1\% reduction in a Eurozone periphery country's government spending leads to an increase of $1.38 \%, 2.42 \%$ and $3.32 \%$ in the short-, medium- and long-run, respectively, of male suicides rates between 65 and 89 years of age in the Eurozone periphery. In addition, unemployment benefits and strict employment protection legislation can help mitigate the negative effects of fiscal austerity on suicide mortality.

These results have important implications for policy makers in the domain of economics and health across Europe. Economic and financial issues have been dominating policy making in the Eurozone, while health and inequalities in health remained relatively low key. Given that economic and social policy decisions have profound effects for health and its fair distribution, health equity should be an important measure of the effectiveness of social and economic policy making, in addition to wealth equity.

The case is strong for governments, as well as European leaders and policy makers, who arguably need to intervene more boldly to protect the most vulnerable and distressed populations from the effects of the crisis and the subsequent fiscal consolidation/austerity measures. That is, different policy sectors should be encouraged to consider and value all major intersectoral impacts of economic policy to society as a whole, including health. For instance, by adopting redistributive policies and by targeted investment in some particular aspects of social protection, governments can promote sustainable health and minimize some of the negative effects of the crisis and fiscal austerity on health. Highly targeted social welfare programmes could help mitigate the health effects of some economic crises, including mental health problems due to increased unemployment (e.g., Vinokur et al., 1991). Put differently, we advocate a paradigm shift in political economy to set a new course of policy development where markets and profits 
are explicitly means to human ends and not the other way around. That is, placing health before wealth.

A potential avenue for future research could be a longitudinal analysis of all Eurozone and/or European Union countries, so as to examine whether the effects of fiscal austerity on suicide in countries that did not apply fiscal austerity measures differ to those in countries that applied such measures.

\section{References}

Afonso, A., 2010. Expansionary Fiscal Consolidations in Europe: New Evidence. Applied Economics Letters 17 (2), 105-109.

Afonso, A., Sousa, R. M., 2012. The Macroeconomic Effects of Fiscal Policy. Applied Economics 44 (34), 4439-4454.

Ahmad, O., Boschi-Pinto, C., Lopez, A. D., Murray, C. J. L., Lozano, R Inoue, M., 2012. Age Standardization of Rates: A New WHO Standard. World Health Organization, GPE Discussion Paper Series 31.

Alesina, A., April 2010. Fiscal Adjustments: Lessons from Recent History. Paper prepared for the ECOFIN meeting, Madrid.

Alesina, A., Ardagna, S., 2010. Large Changes in Fiscal Policy: Taxes versus Spending. In: Tax Policy and the Economy, Volume 24. NBER Chapters. National Bureau of Economic Research, Inc, pp. 35-68.

Alesina, A., Di Tella, R., MacCulloch, R., 2004. Inequality and Happiness: Are Europeans and Americans Different? Journal of Public Economics 88 (9-10), 2009-2042. 
Alesina, A., Perotti, R., 1995. Fiscal Expansions and Adjustments in OECD Economies. Economic Policy 21, 207-248.

Allard, G., 2005. Measuring Job Security Over Time: In Search of a Historical Indicator for EPL (Employment Protection Legislation). Working Papers Economia wp05-17, Instituto de Empresa, Area of Economic Environment.

Andrés, A. R., 2005. Income Inequality, Unemployment, and Suicide: A Panel Data Analysis of 15 European Countries. Applied Economics 37 (4), 439-451.

Andriessen, K., 2006. Do we Need to be Cautious in Evaluating Suicide Statistics? European Journal of Public Health 16 (4), 445.

Antonakakis, N., Collins, A., 2014. The Impact of Fiscal Austerity on Suicide: On the Empirics of a Modern Greek Tragedy. Social Science $E$ S Medicine 112, 39-50.

Arellano, M., Bond, S., 1991. Some Tests of Specification for Panel Data: Monte Carlo Evidence and an Application to Employment Equations. Review of Economic Studies 58 (2), 277-297.

Arellano, M., Bover, O., 1995. Another Look at the Instrumental Variable Estimation of ErrorComponents Models. Journal of Econometrics 68 (1), 29-51.

Arie, S., 2013. Has Austerity Brought Europe to the Brink of a Health Disaster? BMJ 346.

Blanchard, O., Perotti, R., 2002. An Empirical Characterization of the Dynamic Effects of Changes in Government Spending and Taxes on Output. The Quarterly Journal of Economics 117 (4), 1329-1368.

Blundell, R., Bond, S., 1998. Initial Conditions and Moment Restrictions in Dynamic Panel Data Models. Journal of Econometrics 87 (1), 115-143. 
Brainerd, E., 2001. Economic Reform and Mortality in the Former Soviet Union: A Study of the Suicide Epidemic in the 1990s. European Economic Review 45 (4-6), 1007-1019.

Branas, C. C., Kastanaki, A. E., Michalodimitrakis, M., Tzougas, J., Kranioti, E. F., Theodorakis, P. N., Carr B, G., Wiebe, D. J., 2015. The Impact of Economic Austerity and Prosperity Events on Suicide in Greece: A 30-year Interrupted Time-series Analysis. British Medical Journal Open 1, 1-11.

Breuer, C., 2014. Unemployment and Suicide Mortality: Evidence from Regional Panel Data in Europe. Health Economics.

Breuer, C., Rottmann, H., 2014. Do Labor Market Institutions Influence Suicide Mortality? An International Panel Data Analysis. CESifo Working Paper Series 4875, CESifo Group Munich. URL http://ideas.repec.org/p/ces/ceswps/_4875.html

Bruno, G. S., 2005a. Approximating the Bias of the LSDV Estimator for Dynamic Unbalanced Panel Data Models. Economics Letters 87 (3), 361-366.

Bruno, G. S. F., 2005b. Estimation and Inference in Dynamic Unbalanced Panel-Data Models with a Small Number of Individuals. Stata Journal 5 (4), 473-500.

Chen, J., Choi, Y. J., Mori, K., Sawada, Y., Sugano, S., 2012. Socio-Economic Studies On Suicide: A Survey. Journal of Economic Surveys 26 (2), 271-306.

De Vogli, R., 2014. The Financial Crisis, Health and Health Inequities in Europe: The Need for Regulations, Redistribution and Social Protection. International Journal for Equity in Health $13(1), 58$.

Di Tella, R., MacCulloch, R. J., Oswald, A. J., 2001. Preferences over Inflation and Unemployment: Evidence from Surveys of Happiness. American Economic Review 91 (1), 335-341. 
Di Tella, R., MacCulloch, R. J., Oswald, A. J., 2003. The Macroeconomics of Happiness. The Review of Economics and Statistics 85 (4), 809-827.

Dolan, P., Kavetsos, G., Vandoros, S., 2014. Greasy Roads: The Impact of Bad Financial News on Road Traffic Accidents. Risk Analysis 34 (3), 556-566.

Durkheim, E., 1897. Le Suicide: Étude de Sociologie. Alcan, Paris. (Spaulding, J.A., Simpson, G (Trans.), 1958. Suicide: A Study of Sociology). Free Press, New York.

ECDC, 2012. Risk Assessment on HIV in Greece. European Centre for Disease Prevention and Control.

URL http://ecdc.europa.eu/en/publications/publications/ 20121130-risk-assessment-hiv-in-greece.pdf

Economou, M., Madianos, M., Theleritis, C., Peppou, L. E., Stefanis, C. N., 2011. Increased Suicidality Amid Economic Crisis in Greece. The Lancet 378 (9801), 1459.

Evans, W., Graham, J. D., 1988. Traffic Safety and the Business Cycle. Alcohol, Drugs and Driving 4 (1), 31-38.

Fountoulakis, K. N., Grammatikopoulos, I. A., Koupidis, S. A., Siamouli, M., Theodorakis, P. N., 2012. Health and the Financial Crisis in Greece. The Lancet 379 (9820), 1001-1002.

Giavazzi, F., Pagano, M., 1990. Can Severe Fiscal Contractions Be Expansionary? Tales of Two Small European Countries. In: NBER Macroeconomics Annual 1990, Volume 5. NBER Chapters. National Bureau of Economic Research, Inc, pp. 75-122.

Giavazzi, F., Pagano, M., 1996. Non-Keynesian Effects of Fiscal Policy Changes: International Evidence and the Swedish Experience. Swedish Economic Policy Review (3), 67-103. 
Gili, M., Roca, M., Basu, S., McKee, M., Stuckler, D., 2013. The Mental Health Risks of Economic Crisis in Spain: Evidence from Primary Care Centres, 2006 and 2010. The European Journal of Public Health 23 (1), 103-108.

Giudice, G., Turrini, A. A., Veld, J. i., May 2004. Non-Keynesian Fiscal Consolidation in the EU? Ex Post Evidence and Ex Ante Analysis. CEPR Discussion Papers 4388, C.E.P.R. Discussion Papers.

Hamermesh, D. S., Soss, N. M., 1974. An Economic Theory of Suicide. Journal of Political Economy $82(1), 83-98$.

ILO, 2014. Global Employment Trends 2014: Risk of a Jobless Recovery? International Labour Organization.

IMF, 2010. Will It Hurt? Macroeconomic Effects of Fiscal Consolidation, in: World Economic Outlook, Chapter 3. International Monetary Fund.

IMF, 2013. World Economic Outlook October 2013: Transitions and Tensions. International Monetary Fund, IMF.

Judson, R. A., Owen, A. L., 1999. Estimating Dynamic Panel Data Models: A Guide for Macroeconomists. Economics Letters 65 (1), 9-15.

Kaplanoglou, G., Rapanos, V. T., Bardakas, 1. C., May 2014. Does Fairness Matter for the Success of Fiscal Consolidation? Working Papers 180, Bank of Greece.

Karanikolos, M., Mladovsky, P., Cylus, J., Thomson, S., Basu, S., Stuckler, D., Mackenbach, J. P., McKee, M., 2013. Financial Crisis, Austerity, and Health in Europe. The Lancet 381 (9874), 1323-1331. 
Kentikelenis, A., Karanikolos, M., Papanicolas, I., Basu, S., McKee, M., Stuckler, D., 2011. Health Effects of Financial Crisis: Omens of a Greek Tragedy. The Lancet 378 (9801), 14571458.

Kentikelenis, A., Karanikolos, M., Papanicolas, I., Basu, S., McKee, M., Stuckler, D., 2012. Health and the Financial Crisis in Greece - Authors' Reply. The Lancet 379 (9820), 1002.

Lawson, K., Mason, H., McIntosh, E., Donaldson, C., 2014. Priority Setting in Public Health. In: Culyer, A. J. (Ed.), Encyclopedia of Health Economics. Elsevier, San Diego, pp. 155-162.

Marmot, M. G., 2012. Policy Making with Health Equity at its Heart. The Journal of the American Medical Association (JAMA) 307 (19), 2033-2034.

McKee-Ryan, F., Song, Z., Wanberg, C. R., Kinicki, A. J., 2005. Psychological and physical well-being during unemployment: A meta-analytic study. The Journal of Applied Psychology $90(1), 53-76$.

Minoiu, C., Andres, A. R., 2008. The Effect of Public Spending on Suicide: Evidence from U.S. State Data. The Journal of Socio-Economics 37 (1), 237-261.

Neumayer, E., 2003. Are Socioeconomic Factors Valid Determinants of Suicide? Controlling for National Cultures of Suicide with Fixed Effects Estimation. Cross-Cultural Research 37, $307-329$.

Nickell, S. J., 1981. Biases in Dynamic Models with Fixed Effects. Econometrica 49 (6), 14171426.

Roca, M., Gili, M., Garcia-Campayo, J., Garca-Toro, M., 2013. Economic Crisis and Mental Health in Spain. The Lancet 382 (9909), 1977-1978. 
Roodman, D., 2009. How to Do xtabond2: An Introduction to Difference and System GMM in Stata. Stata Journal 9 (1), 86-136.

Ruhm, C. J., 1995. Economic Conditions and Alcohol Problems. Journal of Health Economics $14(5), 583-603$.

Ruhm, C. J., 2000. Are Recessions Good for Your Health? The Quarterly Journal of Economics $115(2), 617-650$.

Sainsbury, P., Jenkins, J. S., 1982. The Accuracy of Officially Reported Suicide Statistics for Purposes of Epidemiological Research. Journal of Epidemiology and Community Health 36 (1), $43-48$.

Schaltegger, C. A., Weder, M., 2014. Austerity, Inequality and Politics. European Journal of Political Economy 35, 1-22.

Shoss, M. K., Penney, L. M., 2012. The Economy and Absenteeism: A Macro-Level Study.

Stuckler, D., Basu, S., Suhrcke, M., Coutts, A., McKee, M., 2009. The Public Health Effect of Economic Crises and Alternative Policy Responses in Europe: an Empirical Analysis. The Lancet 374 (9686), 315-323.

Vandoros, S., Hessel, P., Leone, T., Avendano, M., 2013. Have Health Trends Worsened in Greece as a Result of the Financial Crisis? A Quasi-Experimental Approach. The European Journal of Public Health 23 (5), 727-731.

Vinokur, A. D., van Ryn, M., Gramlich, E. M., Price, R. H., 1991. Long-Term Follow-up and Benefit-Cost Analysis of the Jobs Program: A Preventive Intervention for the Unemployed. The Journal of Applied Psychology 76 (2), 213-219. 
Viren, M., 2005. Suicide and Business Cycles: New Empirical Evidence. Applied Economics Letters 12 (14), 887-891.

Webb, R. T., Kapur, N., 2015. Suicide, Unemployment, and the Effect of Economic Recession. Lancet Psychiatry.

Zavras, D., Tsiantou, V., Pavi, E., Mylona, K., Kyriopoulos, J., 2013. Impact of Economic Crisis and other Demographic and Socio-Economic Factors on Self-Rated Health in Greece. The European Journal of Public Health 23 (2), 206-210. 
Figure 1: Government debt, deficit, unemployment rate, and real GDP per capita (growth), 2007-2013

Government debt as a \% of GDP 200.0

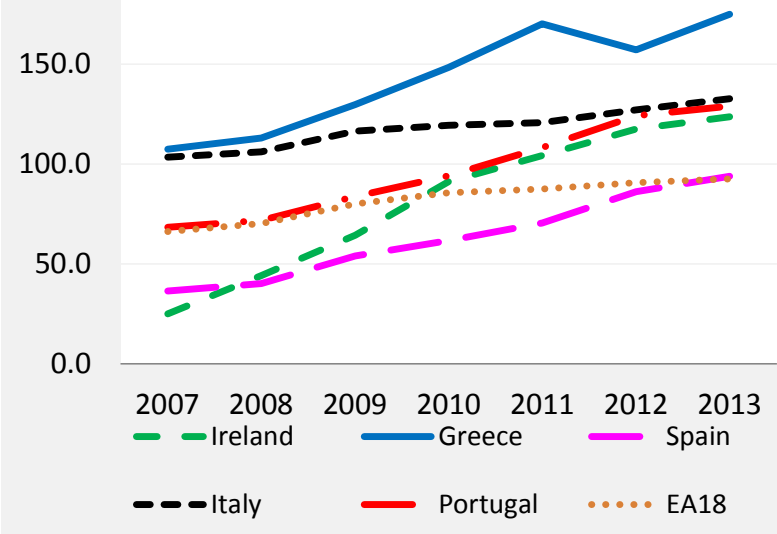

Unemployment rate in \%

30.0

25.0

20.0

15.0

10.0

5.0

0.0

$\begin{array}{lllllll}2007 & 2008 & 2009 & 2010 & 2011 & 2012 & 2013\end{array}$

- Ireland -Greece Spain

- - Italy Portugal..... EA18

GDP per capita (at constant 2005 Euro)

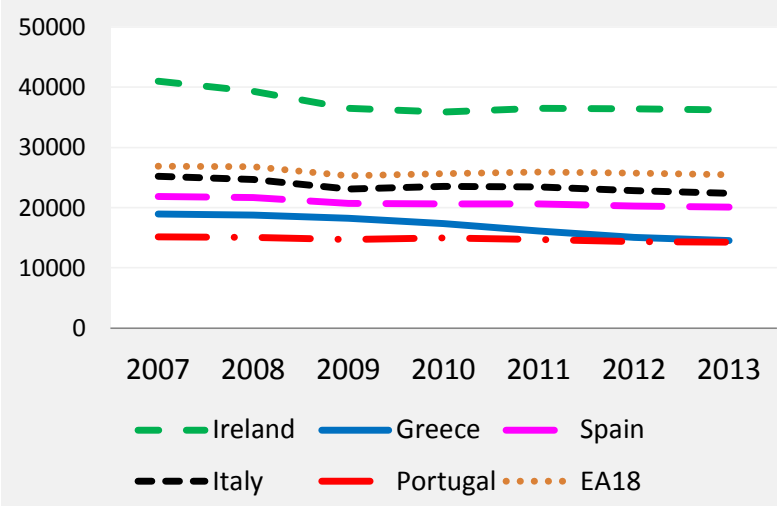

\section{Government deficit/surplus as a} $\%$ of GDP

5.0

0.0

$-5.0$

$-10.0$

$-15.0$

$-20.0$

$-25.0$

$-30.0$

$-35.0$

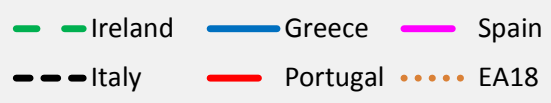

Youth unemployment rate in \% (less than 25 years)

70.0

60.0

50.0

40.0

30.0

20.0

10.0

0.0

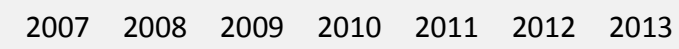

- -Ireland Greece Spain

-- Italy — Portugal..... EA18

Real GDP per capita growth in \%

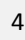

2

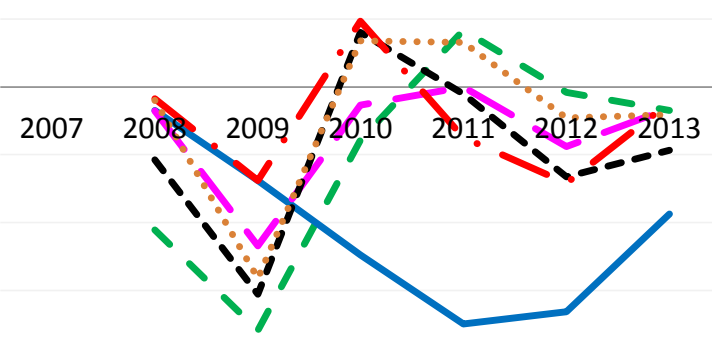

- Ireland Greece $\longrightarrow$ Spain

—- Italy Portugal..... EA18

Source: Eurostat. 
Figure 2: Suicide rates per 100,000 inhabitants (\%), by country, 1968-2012
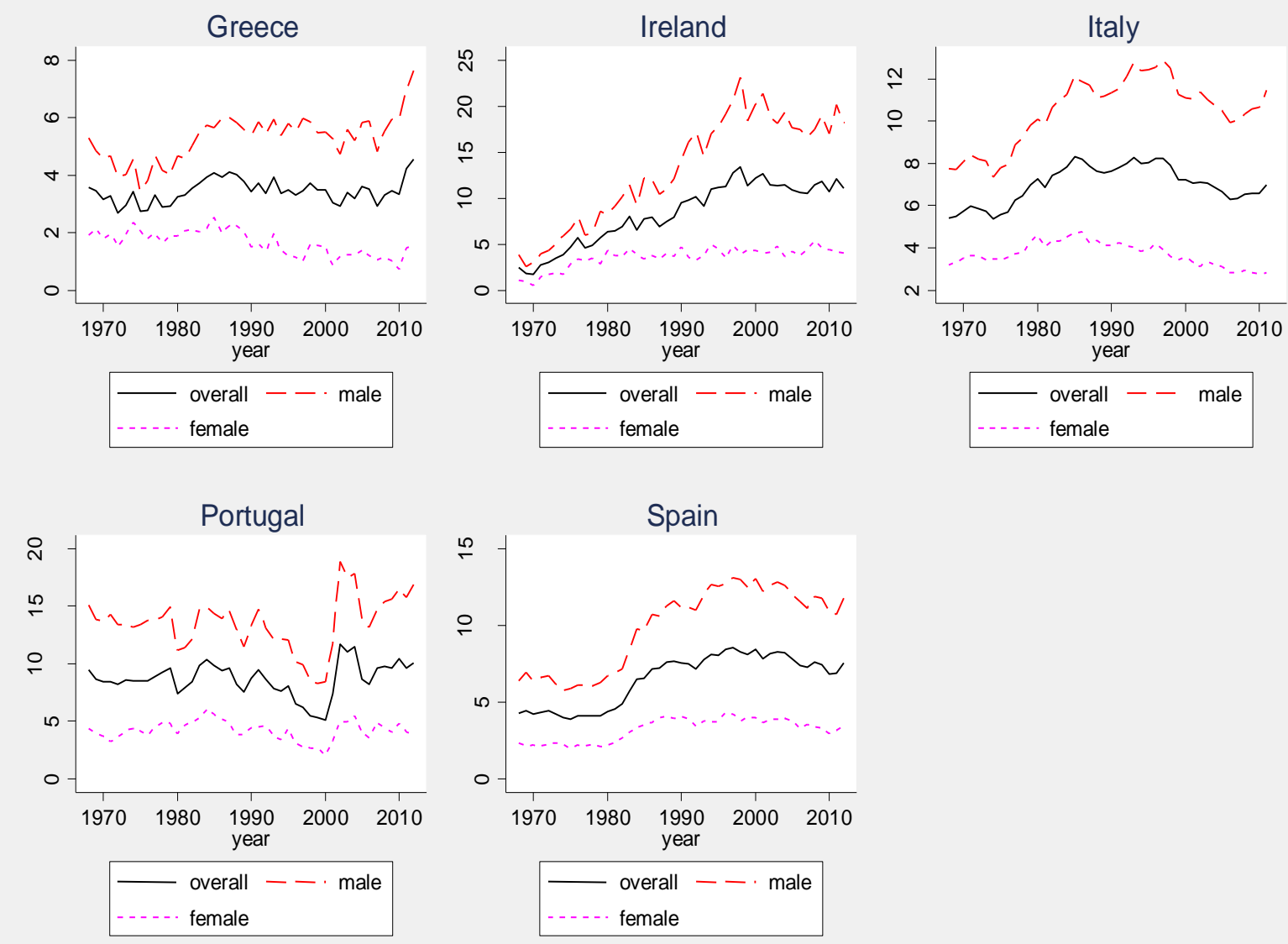

Source: WHO. 
Figure 3: Average suicide rates by age group and gender in the Eurozone periphery, 1968-2012
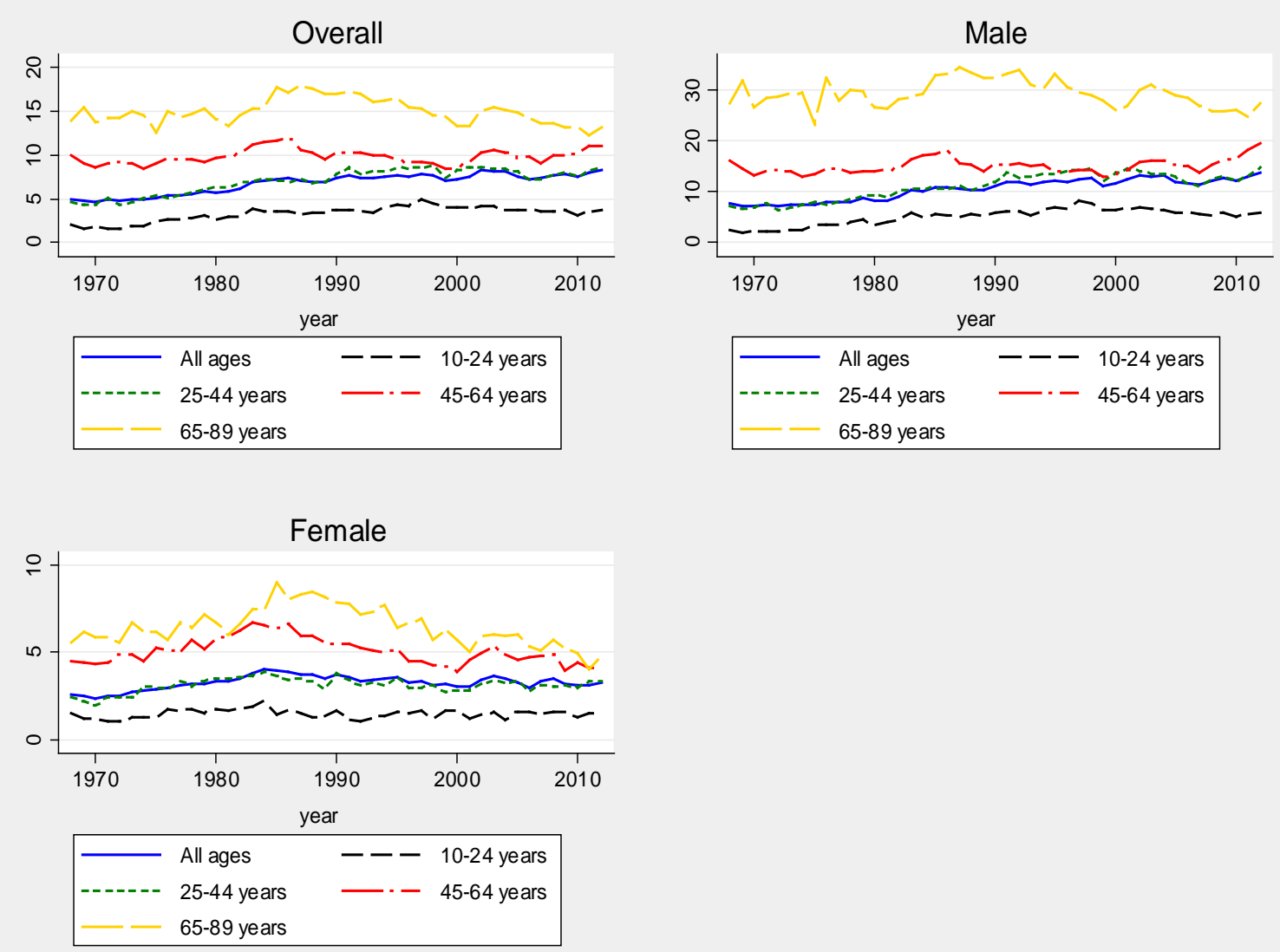

Source: WHO. 
Figure 4: Real per capita GDP growth, government expenditure, budget deficit and public debt, $1968-2012$
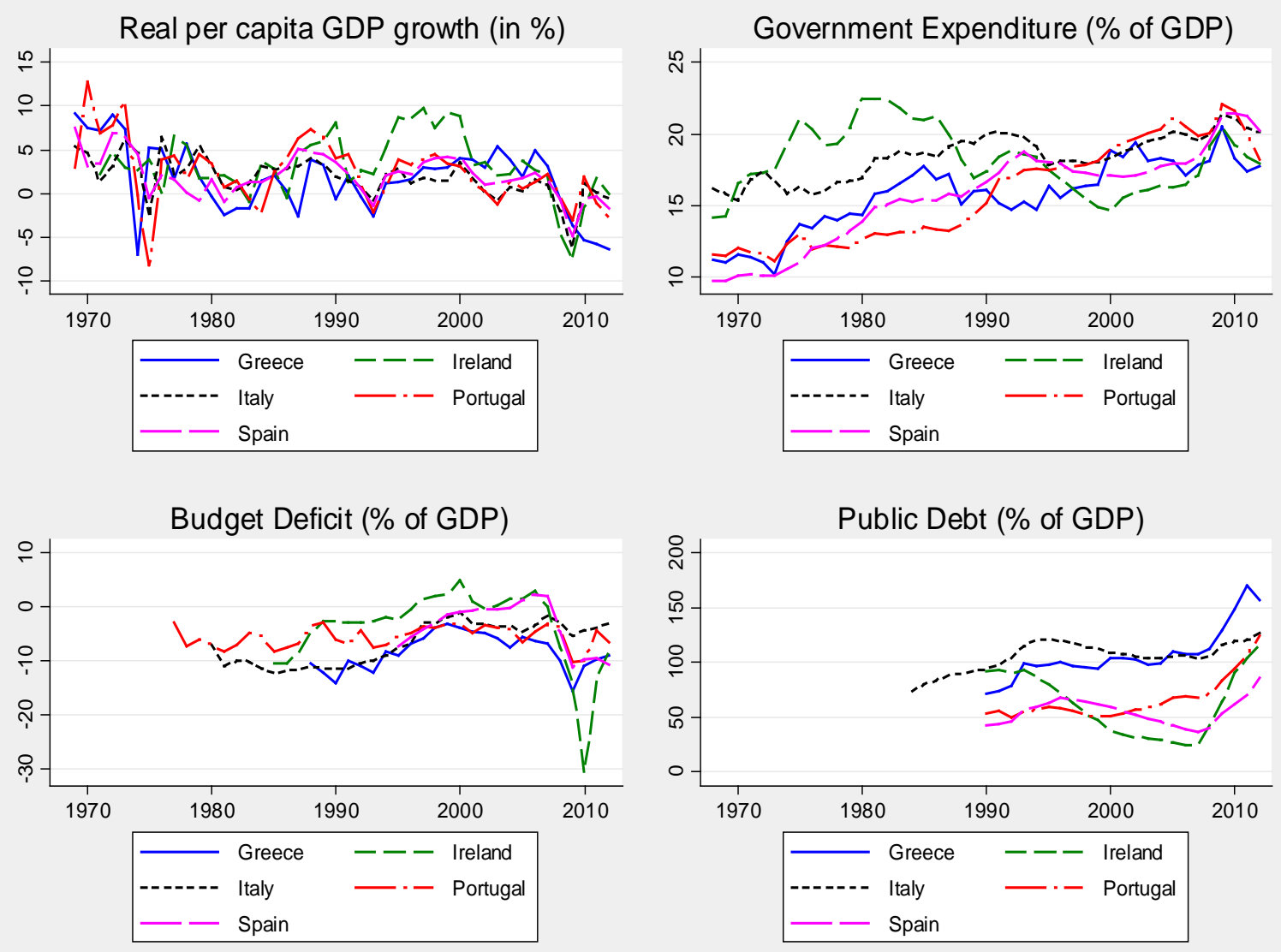

Source: Ameco, WDI. 
Figure 5: Cumulative effect of a sustained 1\% reduction in Eurozone periphery government spending on suicide rates

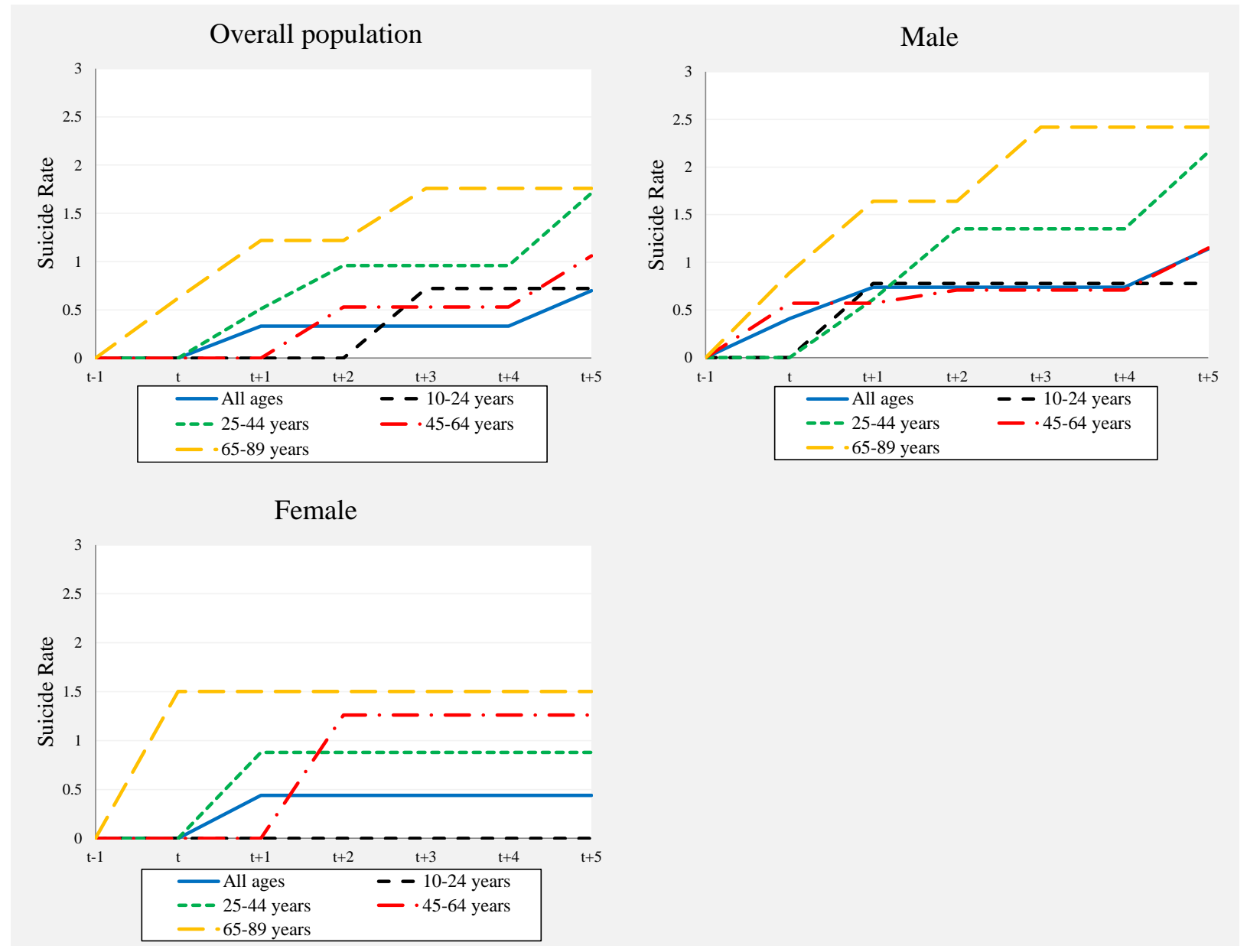

Note: The cumulative effects of a sustained 1\% reduction in government spending on suicides is reported only for those coefficients found significant, at least at the $10 \%$ level, in the estimation results reported in Table 5 . Insignificant values reported in Table 5 receive 0 values. 


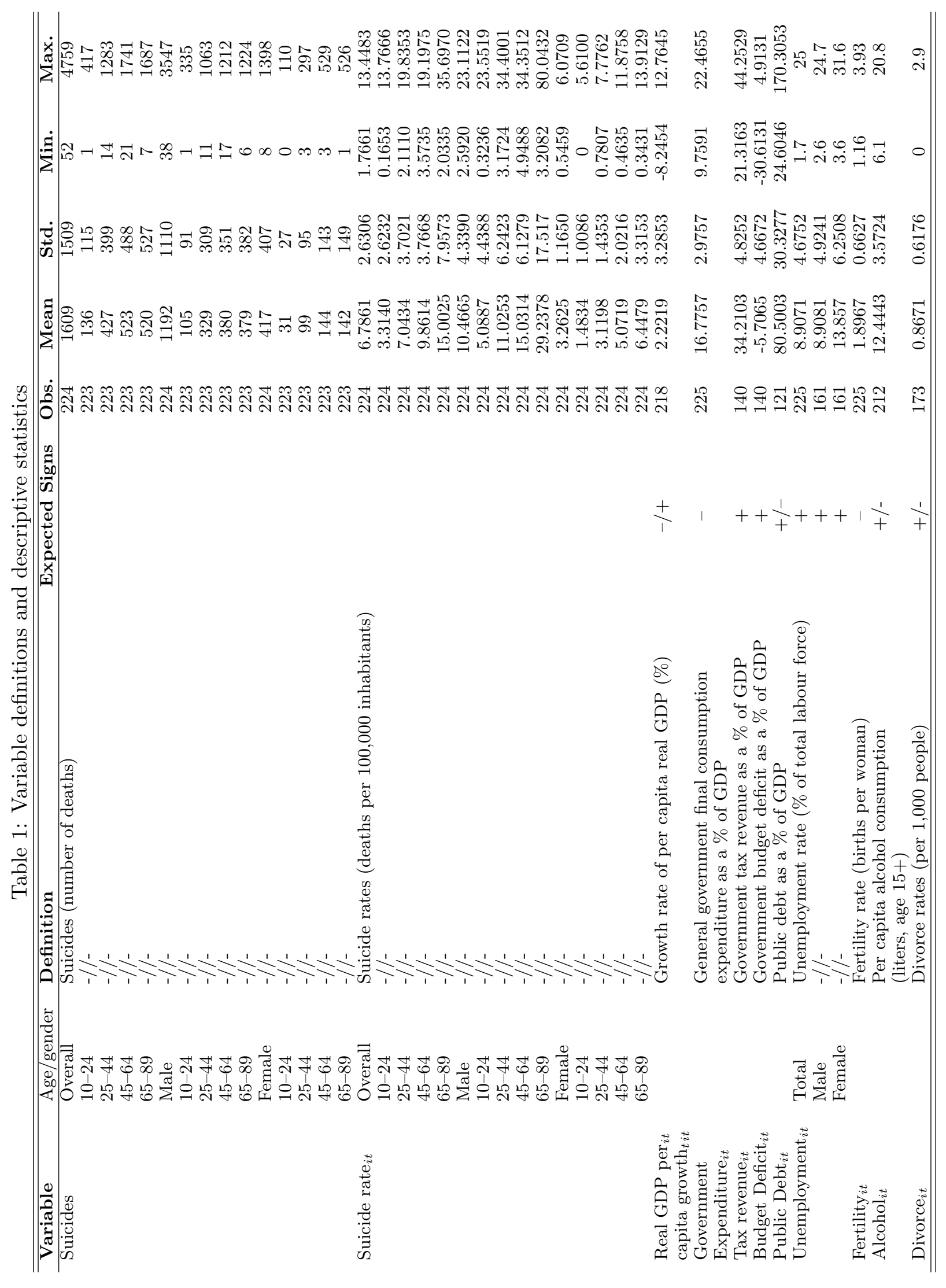




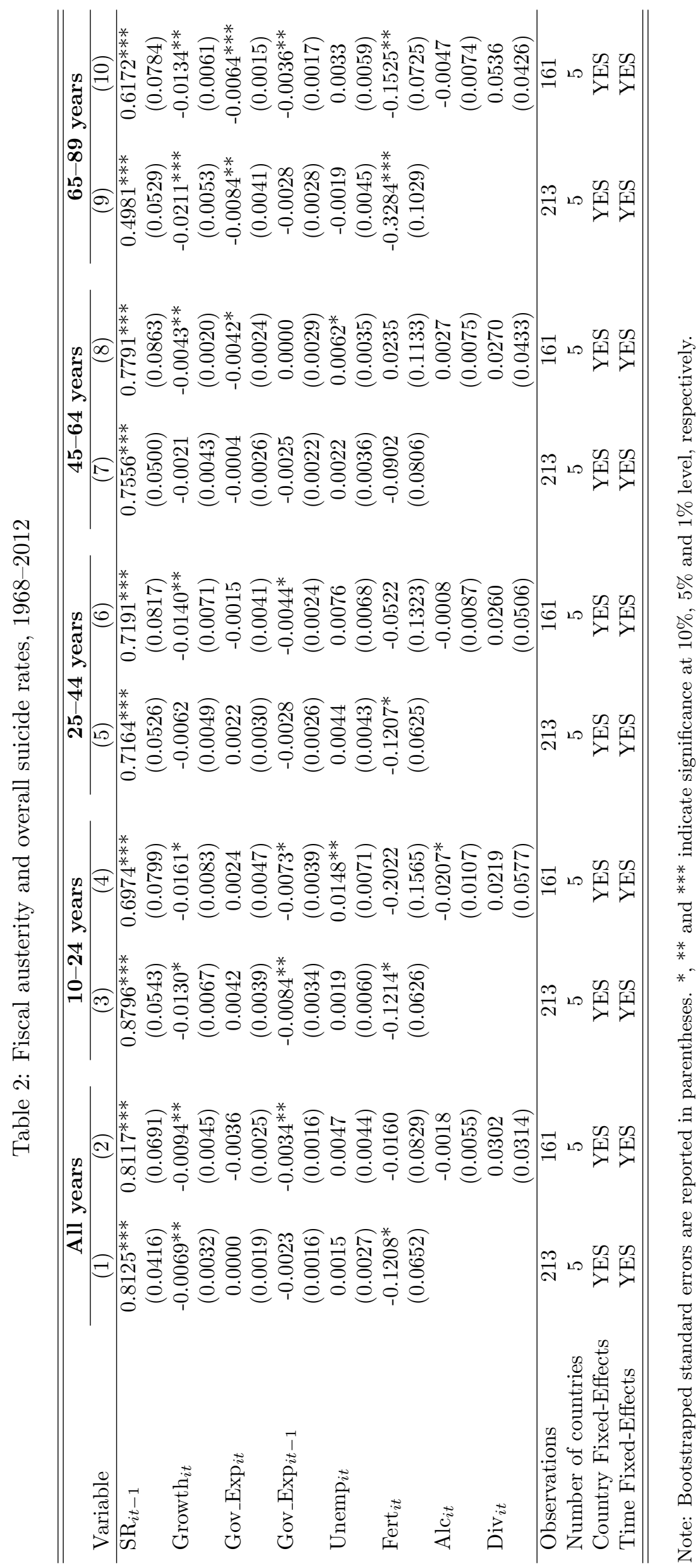




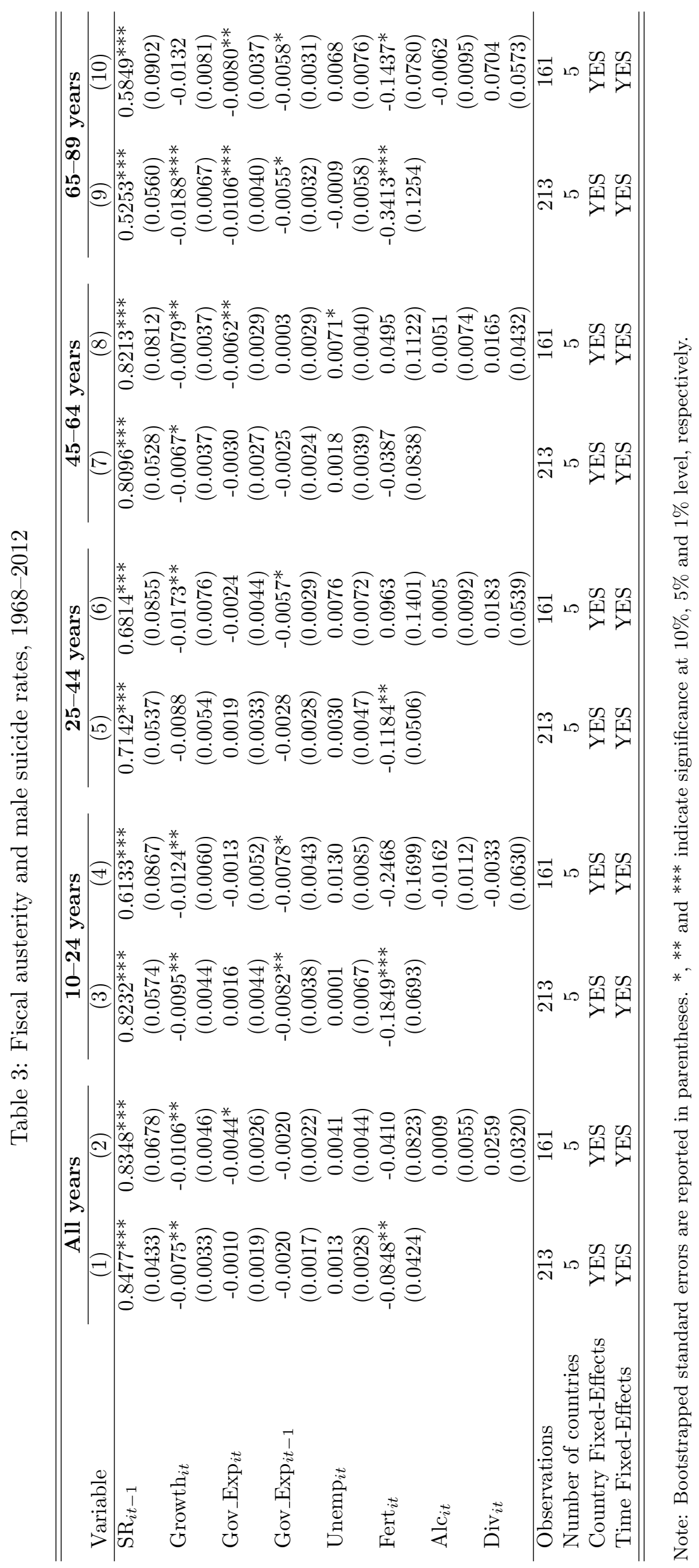




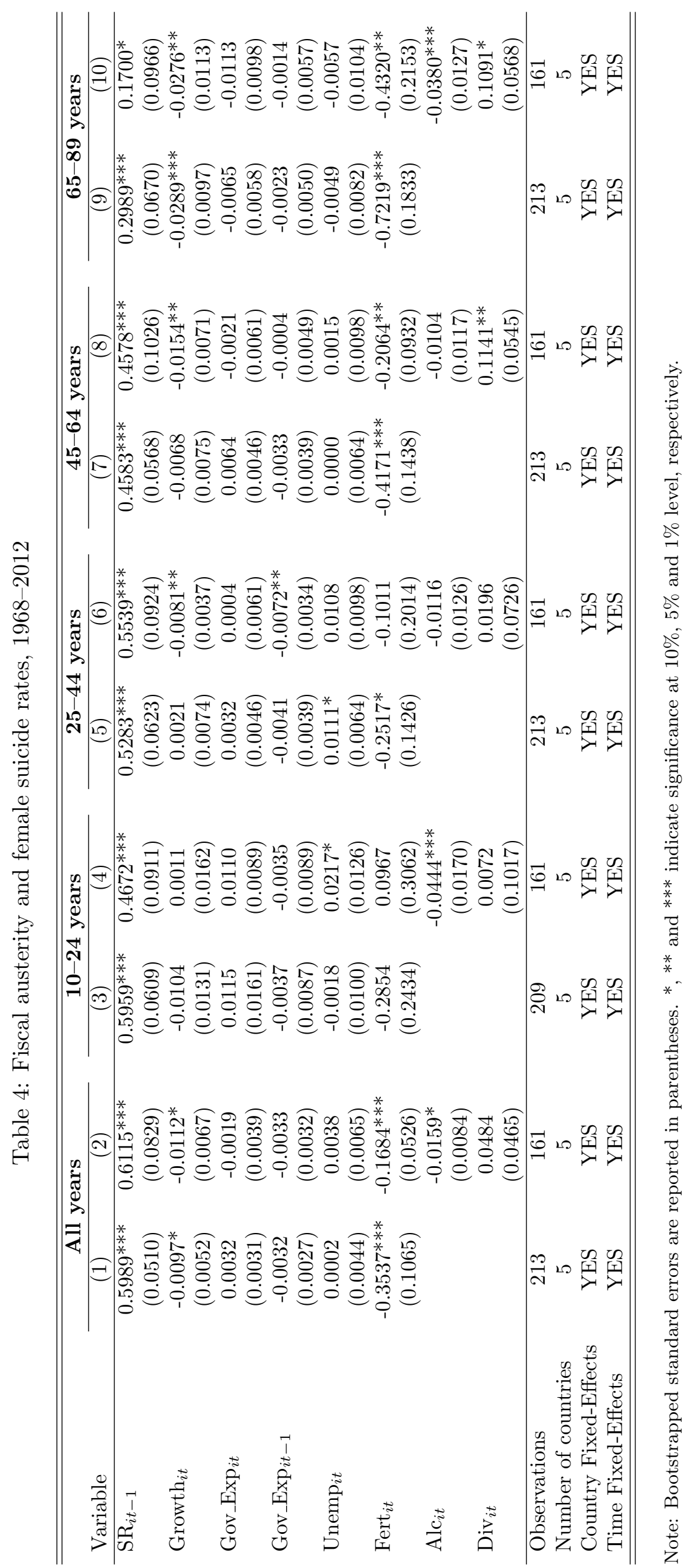


Table 5: Medium-run predicted effect of a sustained 1\% reduction in government spending beginning in year $t$

\begin{tabular}{|c|c|c|c|c|c|c|}
\hline \multicolumn{7}{|c|}{ Panel A: overall suicide rates } \\
\hline Age & $t$ & $t+1$ & $t+2$ & $t+3$ & $t+4$ & $t+5$ \\
\hline All ages & $0.32 \%$ & $0.33 \% * *$ & $0.30 \%$ & $-0.11 \%$ & $-0.06 \%$ & $0.37 \% * *$ \\
\hline $10-24$ years & $-0.23 \%$ & $0.63 \%$ & $-0.20 \%$ & $0.72 \% *$ & $-0.63 \%$ & $0.28 \%$ \\
\hline $25-44$ years & $0.10 \%$ & $0.51 \% * *$ & $0.45 \% *$ & $-0.27 \%$ & $0.21 \%$ & $0.75 \% * * *$ \\
\hline $45-64$ years & $0.26 \%$ & $0.07 \%$ & $0.53 \% *$ & $-0.11 \%$ & $0.09 \%$ & $0.53 \% * *$ \\
\hline $65-89$ years & $0.62 \% * *$ & $0.60 \% * *$ & $-0.02 \%$ & $0.54 \% *$ & $-0.14 \%$ & $-0.11 \%$ \\
\hline \multicolumn{7}{|c|}{ Panel B: male suicide rates } \\
\hline Age & $t$ & $t+1$ & $t+2$ & $t+3$ & $t+4$ & $t+5$ \\
\hline All ages & $0.41 \% *$ & $0.33 \% *$ & $0.21 \%$ & $-0.05 \%$ & $0.09 \%$ & $0.40 \% * *$ \\
\hline 10-24 years & $0.03 \%$ & $0.78 \% *$ & $0.12 \%$ & $0.55 \%$ & $-0.73 \%$ & $0.55 \%$ \\
\hline 25-44 years & $0.16 \%$ & $0.61 \% * *$ & $0.74 \% *$ & $-0.15 \%$ & $0.28 \%$ & $0.81 \% * * *$ \\
\hline 45-64 years & $0.57 \% * * *$ & $0.05 \%$ & $0.14 \% *$ & $-0.03 \%$ & $0.42 \%$ & $0.44 \% *$ \\
\hline 65-89 years & $0.89 \% * *$ & $0.75 \% * *$ & $0.26 \%$ & $0.78 \% * *$ & $0.19 \%$ & $0.18 \%$ \\
\hline \multicolumn{7}{|c|}{ Panel C: female suicide rates } \\
\hline Age & $t$ & $t+1$ & $t+2$ & $t+3$ & $t+4$ & $t+5$ \\
\hline All ages & $0.19 \%$ & $0.44 \% *$ & $0.52 \%$ & $-0.28 \%$ & $-0.43 \%$ & $0.15 \%$ \\
\hline 10-24 years & $-0.82 \%$ & $0.52 \%$ & $0.30 \%$ & $0.08 \%$ & $0.47 \%$ & $0.49 \%$ \\
\hline 25-44 years & $0.06 \%$ & $0.88 \% *$ & $0.71 \%$ & $-0.42 \%$ & $0.12 \%$ & $0.21 \%$ \\
\hline 45-64 years & $-0.09 \%$ & $0.08 \%$ & $1.26 \% * *$ & $-0.03 \%$ & $-0.61 \%$ & $0.58 \%$ \\
\hline 65-89 years & $1.50 \% * *$ & $0.14 \%$ & $-0.78 \%$ & $0.68 \%$ & $-0.16 \%$ & $-0.41 \%$ \\
\hline
\end{tabular}

Note: Entries show the predicted effect of a $1 \%$ decrease in the Eurozone periphery government spending beginning in year $t$ and continuing through year $t+5$. These predictions are made using the results of regressions similar to those in Tables 2, 3 and 4, with the only exception of the inclusion of fiscal austerity variable lagged up to 5 year periods. ${ }^{*},{ }^{*}$ and $* * *$ indicate significance at $10 \%, 5 \%$ and $1 \%$ level, respectively. 
Table 6: Long-run multiplier of fiscal austerity on suicide rates

\begin{tabular}{lccc}
\hline \hline & Overall suicide rates & Male suicide rates & Female suicide rates \\
\hline All ages & - & - & - \\
10-24 years & - & - & - \\
$25-44$ years & - & - & - \\
$45-64$ years & - & - & - \\
$65-89$ years & $-2.61 \%$ & $-3.32 \%$ & - \\
\hline \hline
\end{tabular}

Note: The long-run multiplier is computed according to equation 3 only for the cases where all the coefficients $\hat{\beta}_{1}, \hat{\beta}_{2}$ and $\hat{\beta}_{3}$ are significant at least at the $10 \%$ level in Tables 2,3 and 4 . 


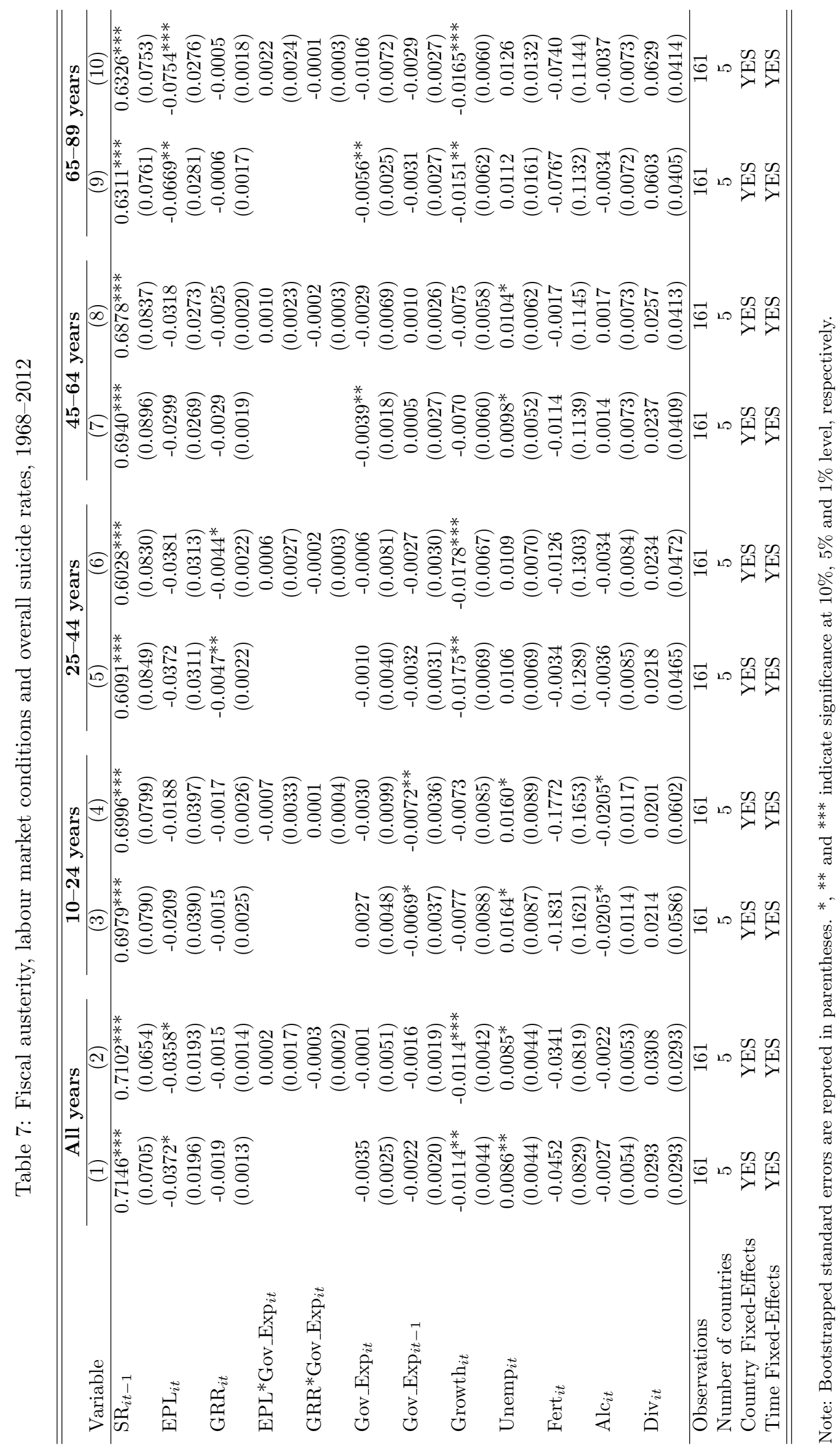




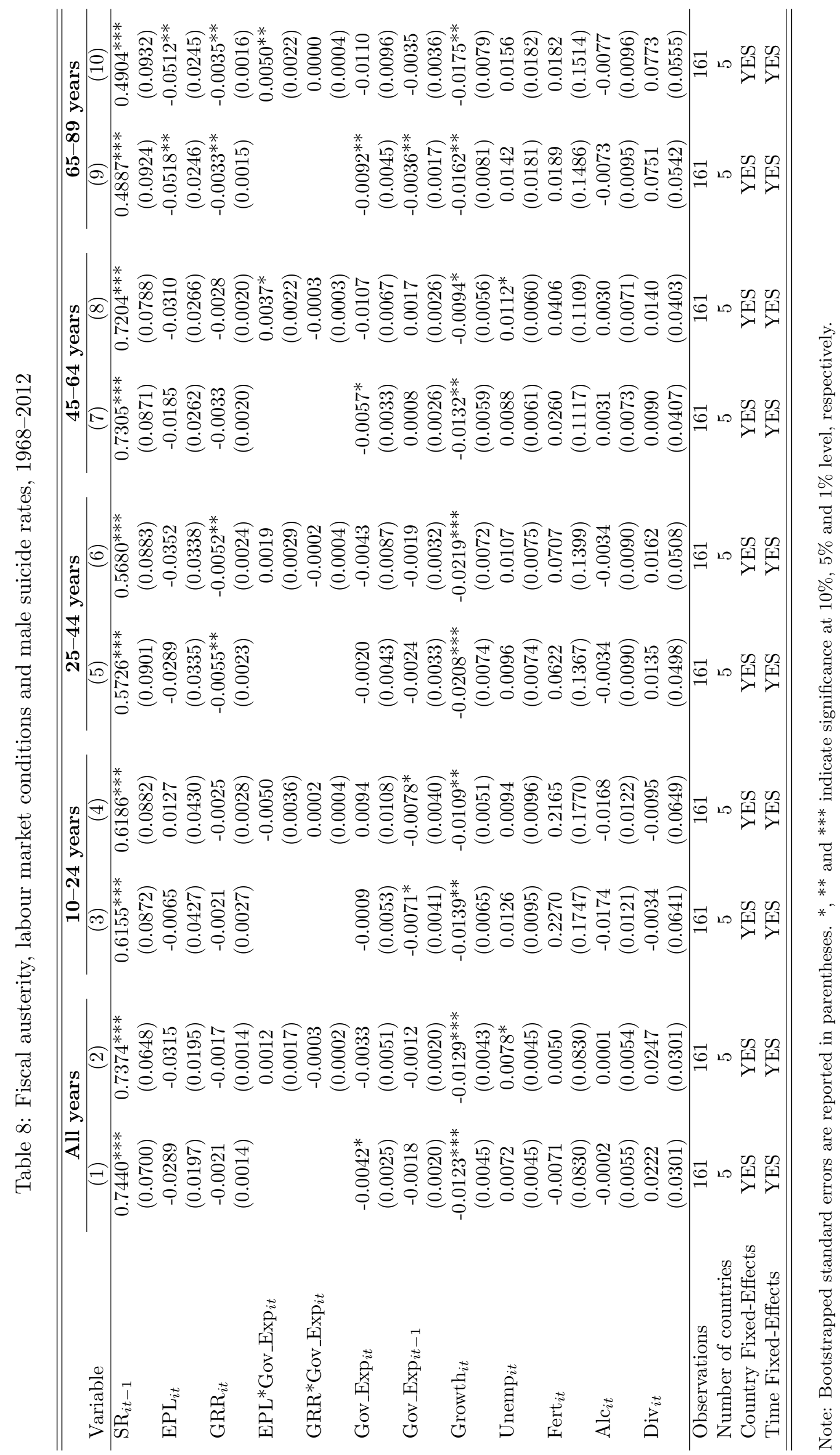




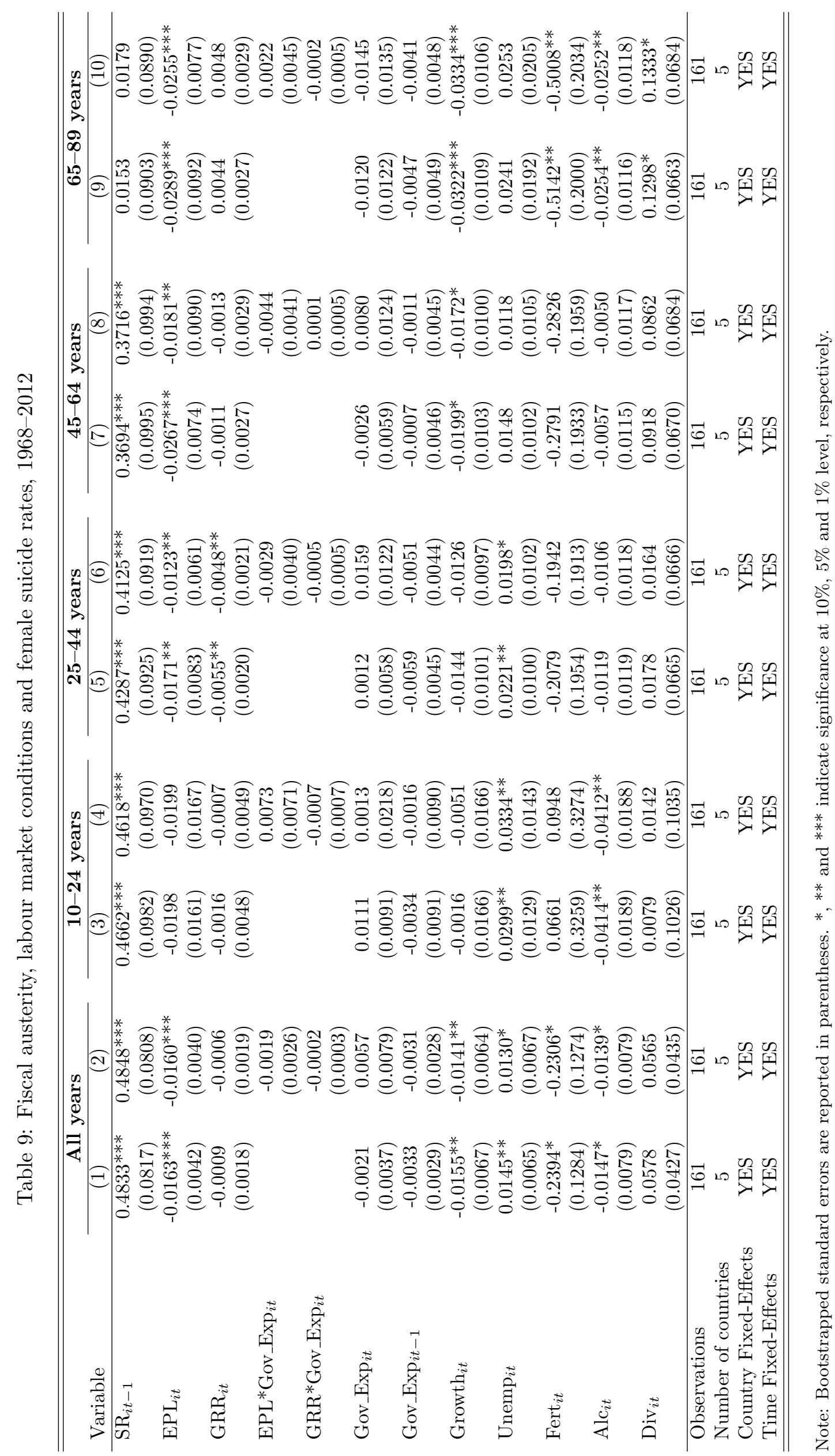




\section{A Online Appendix}

We collect annual observations of suicide statistics for Greece, Ireland, Italy, Portugal and Spain between 1968 and 2012. Suicide data (defined as number of deaths by suicide and self-inflicted injury/intentional self-harm, based on the following international classification of diseases (ICD) codes, ICD-7 codes E963 and E970-E979, ICD-8 and ICD-9 codes E950-E959, ICD-10 codes X60X84) and population data are extracted from the World Health Organization (WHO) Mortality Database $^{1}$ and are extended up to 2012 with data on suicide and population supplemented from the official national statistics of each country ${ }^{2}$ and Eurostat $^{3}$, respectively. There is a consensus and some analytical concern that suicides are underreported in general due to misclassifications (see e.g. Andriessen, 2006; Sainsbury and Jenkins, 1982). Despite this, the total epidemiological picture seems to be reliable and international suicide rates can be compared over time and across countries. Suicide data can have 'a weak validity but an acceptable reliability' (Andriessen, 2006). Therefore, our estimated parameters should be seen as an underestimation of the true effects of fiscal austerity.

Overall unemployment rate data have been obtained from the Annual Macro-Economic (AMECO) database of the European Commission ${ }^{4}$, while gender-specific unemployment rates from the World Development Indicators (WDI) database maintained by the World Bank ${ }^{5}$. The general government final consumption expenditure as a \% of GDP and taxes as a \% of GDP, along with per capita real GDP growth come from the World Bank World Development Indicators (WDI) database ${ }^{6}$ and the government budget deficit as a $\%$ of GDP comes from the

\footnotetext{
${ }^{1}$ http://www . who.int/healthinfo/mortality_data/en/.

${ }^{2}$ Greece: http://www.statistics.gr/portal/page/portal/ESYE/PAGE-database, Ireland: http://www.cso. ie/en/index.html, Italy: http://en.istat.it/dati/db_siti/, Portugal: http://www.ine.pt/xportal/xmain? xpgid=ine_main\&xpid=INE\&xlang=en, Spain: http://www.ine.es/en/welcome.shtml.

${ }^{3} \mathrm{http}$ ///ec.europa.eu/eurostat/statistics-explained/index.php/Causes_of_death_statistics.

${ }^{4}$ http://ec.europa.eu/economy_finance/ameco/user/serie/SelectSerie.cfm.

${ }^{5} \mathrm{http}$ ://data.worldbank.org/indicator/SL.UEM.TOTL.FE.ZS and http://data.worldbank.org/ indicator/SL. UEM. TOTL.MA.ZS.

${ }^{6}$ http://data.worldbank.org/indicator/NE.CON.GOVT.ZS, http://data.worldbank.org/indicator/GC. TAX.TOTL.GD.ZS and http://data.worldbank.org/indicator/NY.GDP.PCAP.KD.
} 
AMECO database ${ }^{7}$. Data on fertility rates come from the World Bank World Development Indicators $(\mathrm{WDI})^{8}$ and Eurostat databases ${ }^{9}$, alcohol consumption from OECD Health database ${ }^{10}$ and divorce rates from EUROSTAT ${ }^{11}$. Finally, data for the labour market institution indicators comes from OECD labour market statistics database ${ }^{12}$ and Allard (2005).

Table A.1: Data availability

\begin{tabular}{lccccc}
\hline \hline Variable & Greece & Ireland & Italy & Portugal & Spain \\
\hline Age and gender specific suicide rates & $1968-2012$ & $1968-2012$ & $1968-2011$ & $1968-2012$ & $1968-2012$ \\
$\begin{array}{l}\text { Real GDP per capita growth } \\
\text { General government final }\end{array}$ & $1968-2012$ & $1970-2012$ & $1968-2012$ & $1968-2012$ & $1968-2012$ \\
consumption expenditure (\% of GDP) & $1968-2012$ & $1968-2012$ & $1968-2012$ & $1968-2012$ & $1968-2012$ \\
$\begin{array}{l}\text { Government budget deficit (\% of GDP) } \\
\text { Tax (\% of GDP) }\end{array}$ & $1968-2012$ & $1968-2012$ & $1968-2012$ & $1968-2012$ & $1968-2012$ \\
Government Debt (\% of GDP) & $1968-2012$ & $1968-2012$ & $1968-2012$ & $1968-2012$ & $1968-2012$ \\
$\begin{array}{l}\text { Real per capita government spending } \\
\text { on public health }\end{array}$ & $1990-2012$ & $1990-2012$ & $1984-2012$ & $1990-2012$ & $1990-2012$ \\
Unemployment rate & $1995-2012$ & $1995-2012$ & $1995-2012$ & $1995-2012$ & $1995-2012$ \\
Fertility rate & $1968-2012$ & $1968-2012$ & $1968-2012$ & $1968-2012$ & $1968-2012$ \\
Alcohol consumption & $1968-2012$ & $1968-2012$ & $1968-2012$ & $1968-2012$ & $1968-2012$ \\
$\begin{array}{l}\text { Divorce rate } \\
\text { Labour market institution indicators }\end{array}$ & $1968-2011$ & $1968-2011$ & $1968-2009$ & $1968-2007$ & $1968-2009$ \\
\hline \hline & $1968-2009$ & $1997-2011$ & $1971-2010$ & $1968-2012$ & $1981-2011$ \\
& & $1968-2011$ & $1968-2011$ & $1968-2011$ & $1968-2011$ \\
\hline
\end{tabular}

A snapshot of the suicide series is presented in Table A.2. Panel A of Table A.2 reveals that the number of overall suicides between 2009 and 2012 (and 2011 for Italy) have increased by $30 \%$ (from 391 to 508 ) in Greece, by $4.56 \%$ (from 3971 to 4152 ) in Italy, by $4 \%$ (from 1025 to 1066) in Portugal, by $3.21 \%$ (from 3429 to 3539 ) in Spain, and declined by $3.8 \%$ (from 527 to 507) in Ireland. Similar changes have also been experienced by male and female suicides. Worryingly, since 2009, the number and rate of suicides are, in general, above their 1968-2012 average values. Selected years for the suicide rates (per 100,000 inhabitants) series reported in Panel B of Table A.2, reveal similar trends as those for the number of suicides in Panel A of the

\footnotetext{
${ }^{7}$ http://ec.europa.eu/economy_finance/ameco/user/serie/SelectSerie.cfm.

${ }^{8}$ http://data. worldbank.org/indicator/SP.DYN. TFRT. IN.

${ }^{9}$ http://ec.europa.eu/eurostat/statistics-explained/index.php/Fertility_statistics.

${ }^{10}$ http://www.oecd-ilibrary.org/social-issues-migration-health/alcohol-consumption_ alcoholcons-table-en.

${ }^{11}$ http://ec.europa.eu/eurostat/statistics-explained/index.php/Marriage_and_divorce_statistics.

12 employment/emp/oecdindicatorsofemploymentprotection.htm\#data and www.oecd.org/els/soc/GRR_EN. $\mathrm{xlsx}$.
} 
same table.

Table A.3 presents suicide rates by time, 5-year age groups and by sex, for a selection of years. According to this table, there is also clear evidence that suicide rates increase with age and that males are more prone to commit suicide than females are, and which are in line with the theoretical justications of Hamermesh and Soss (1974) and Durkheim (1897). 


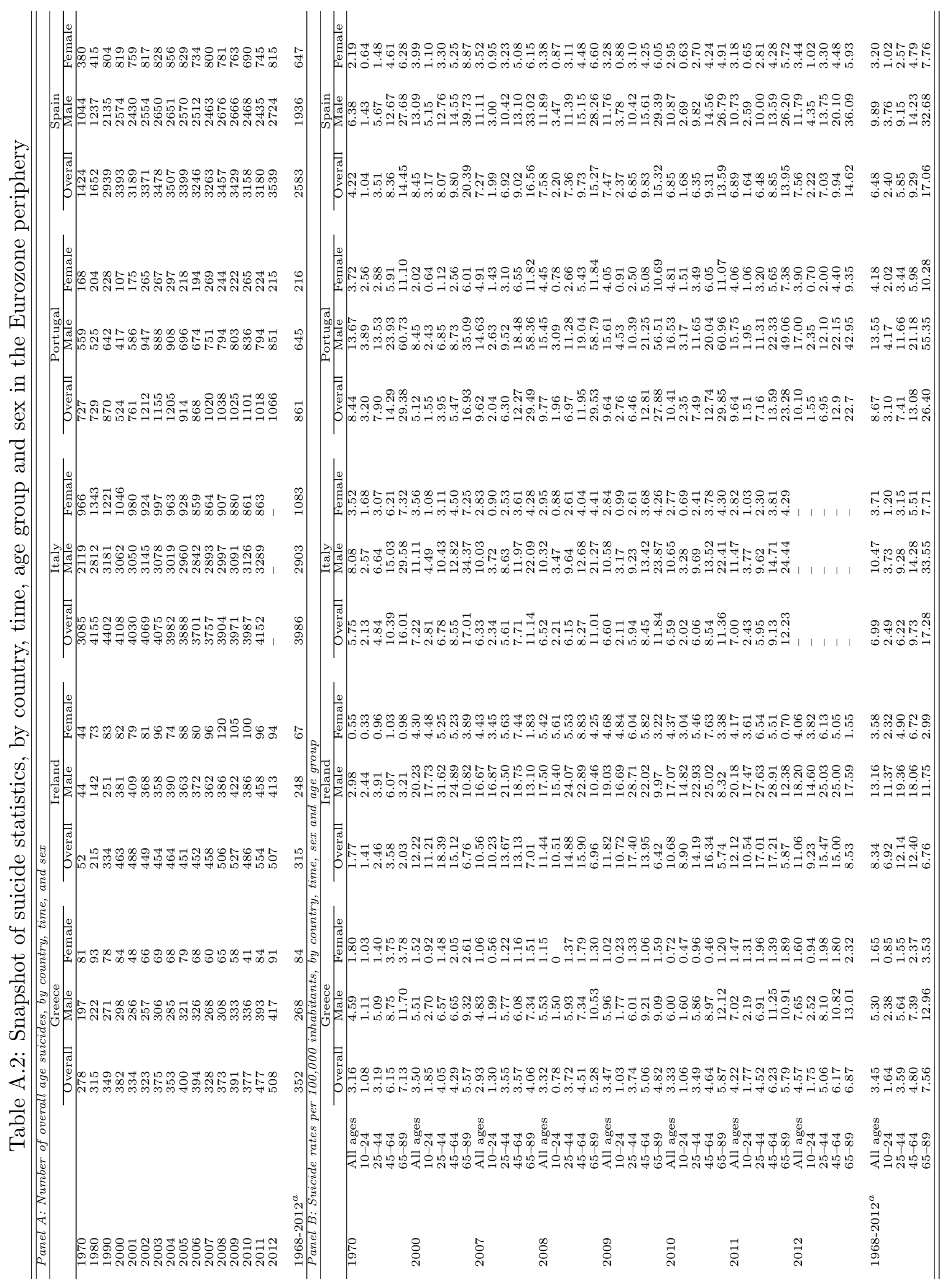




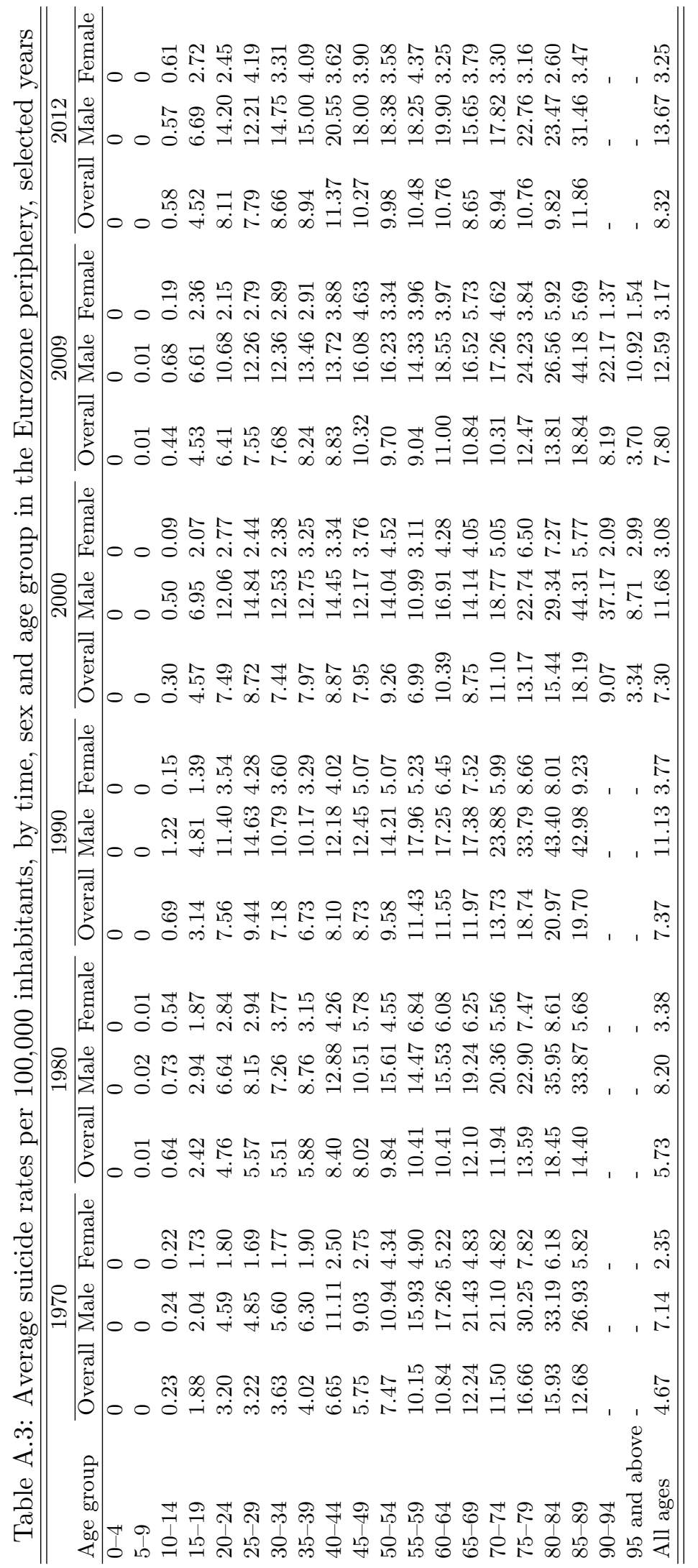

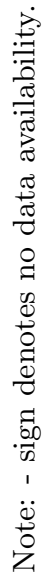




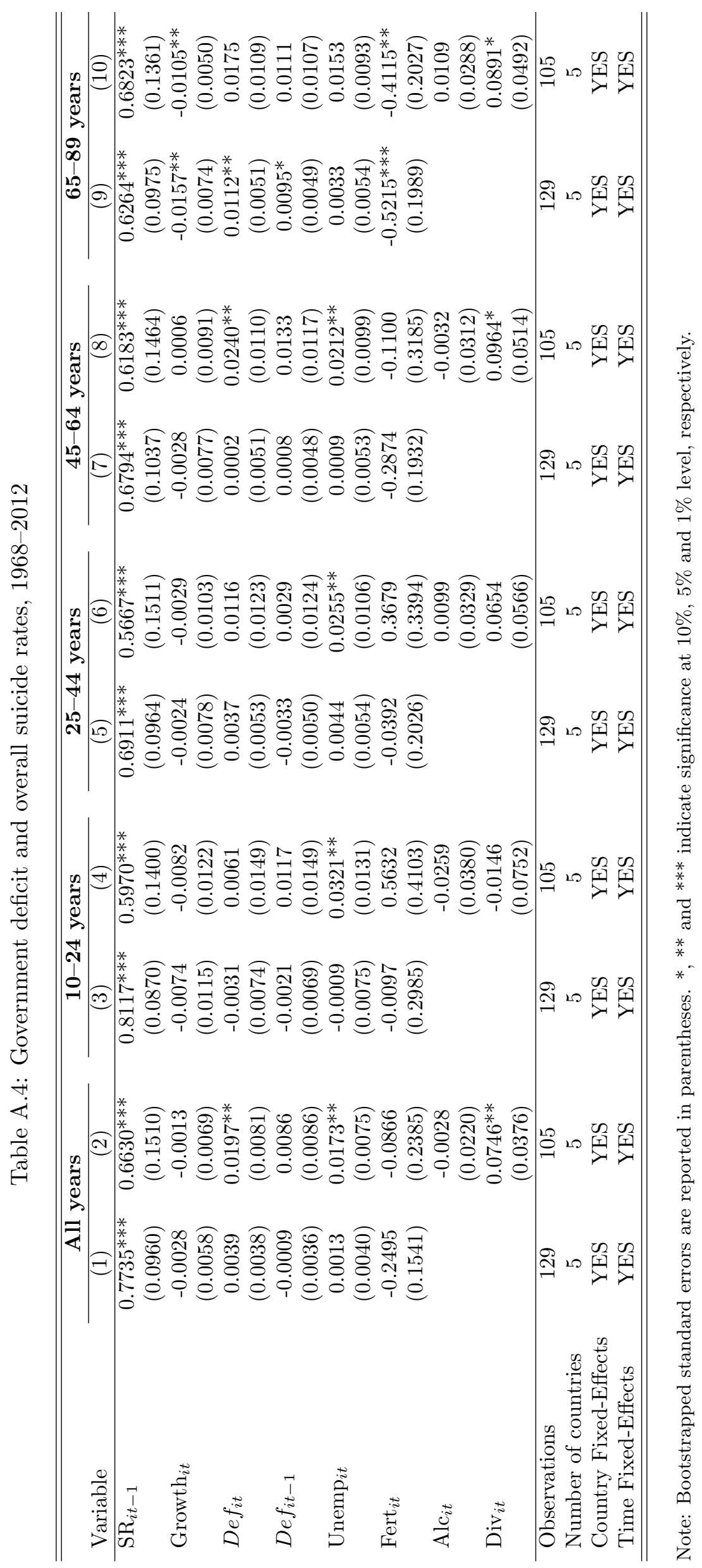




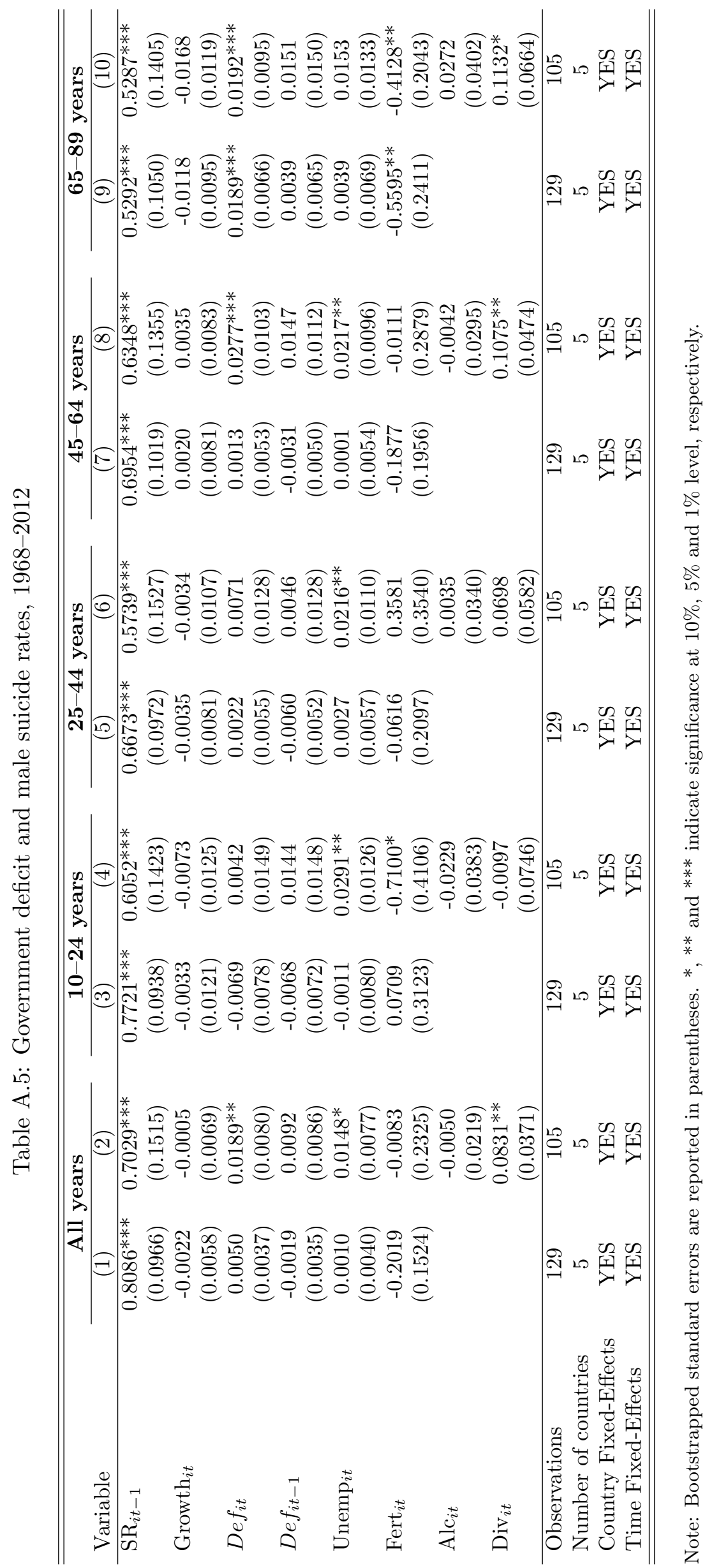




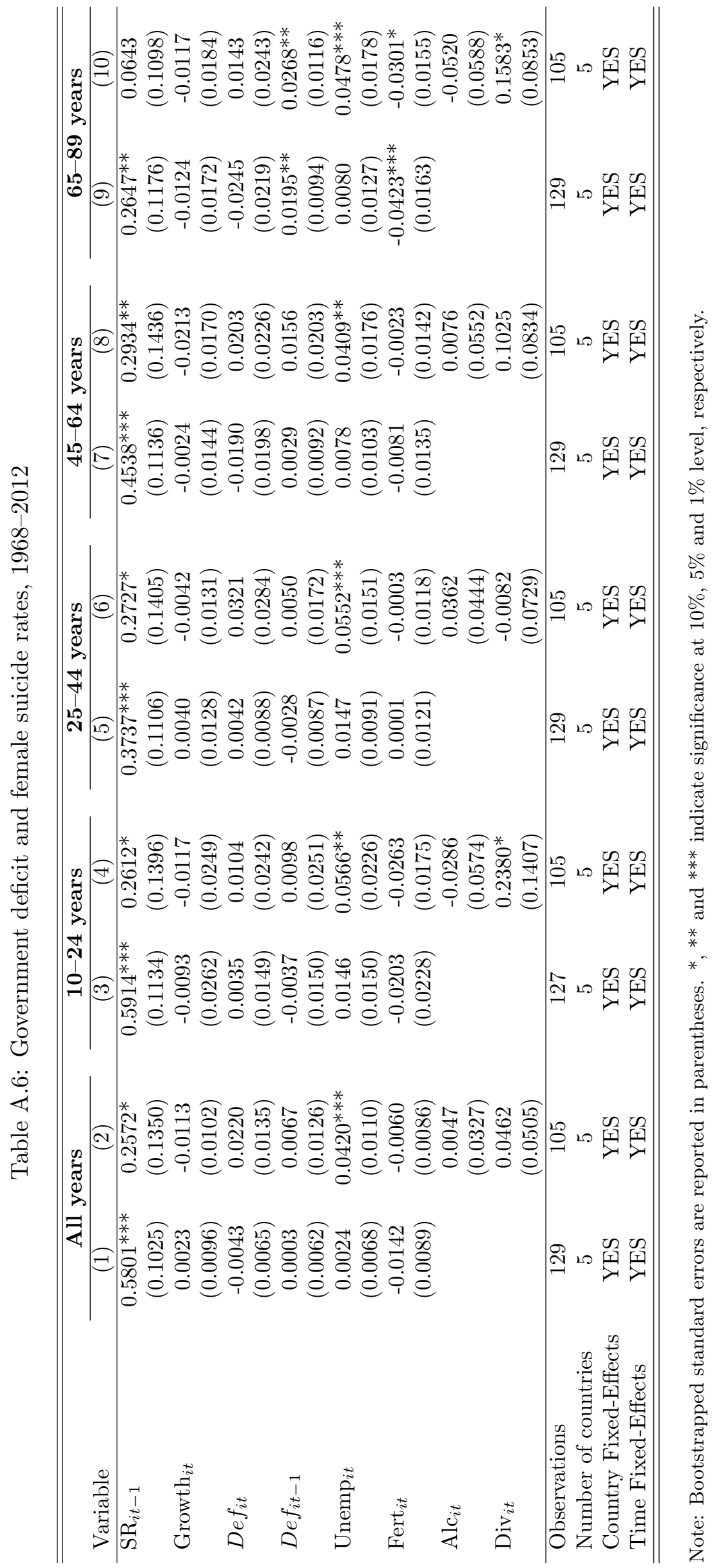




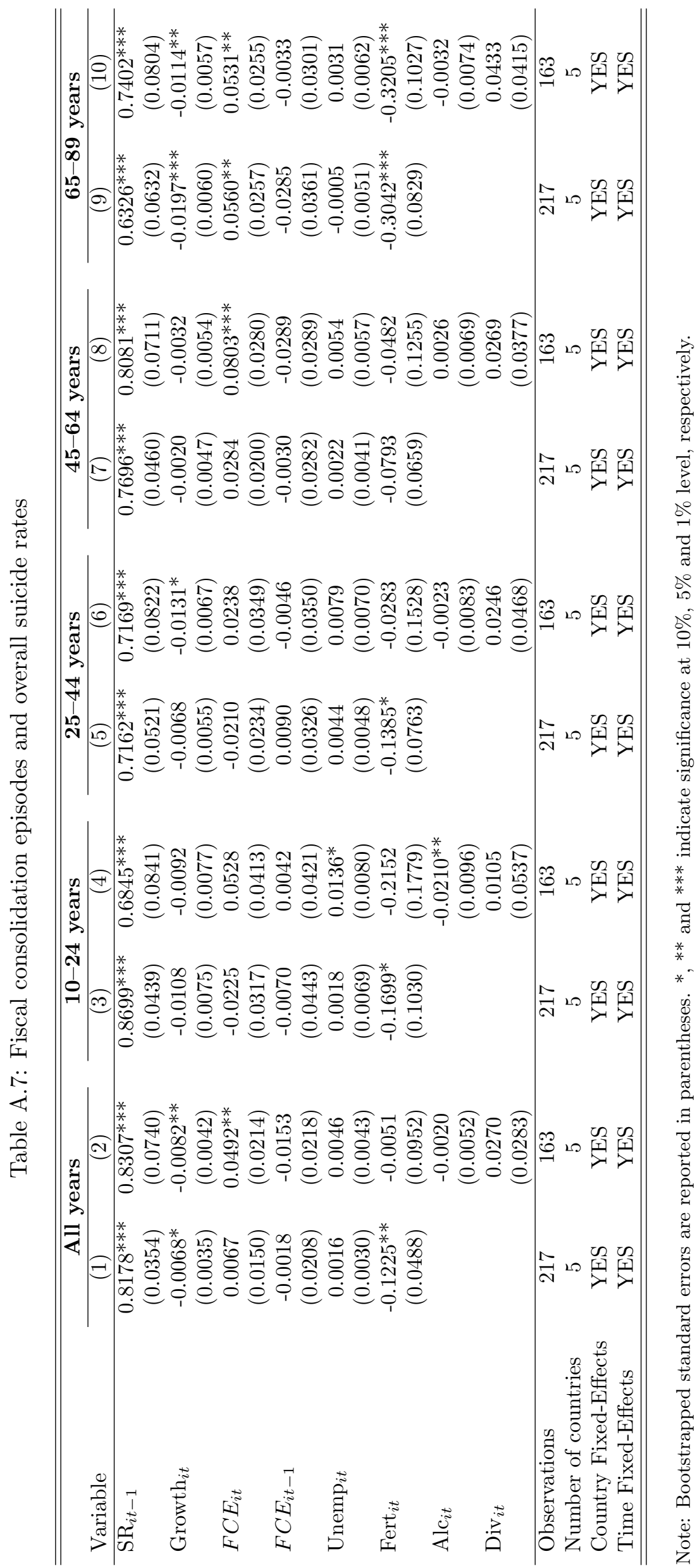




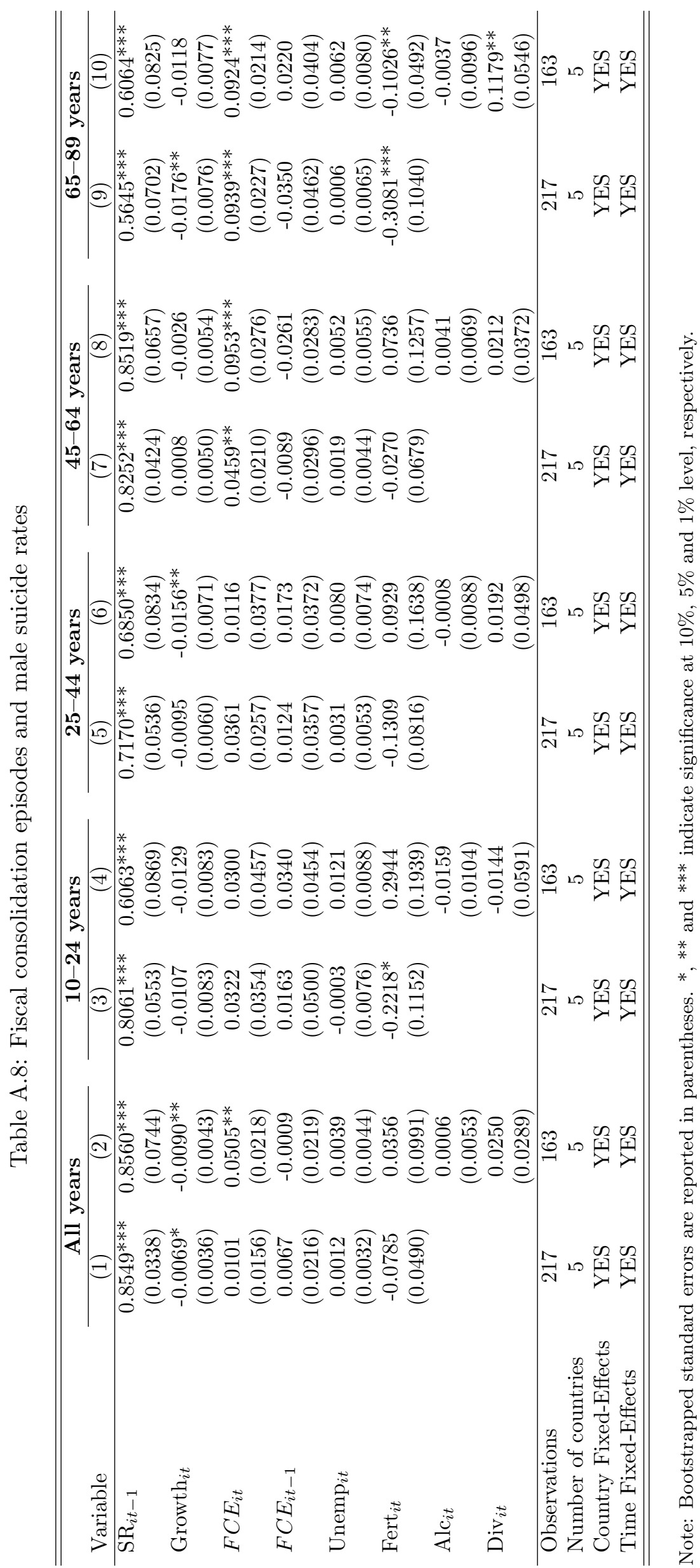




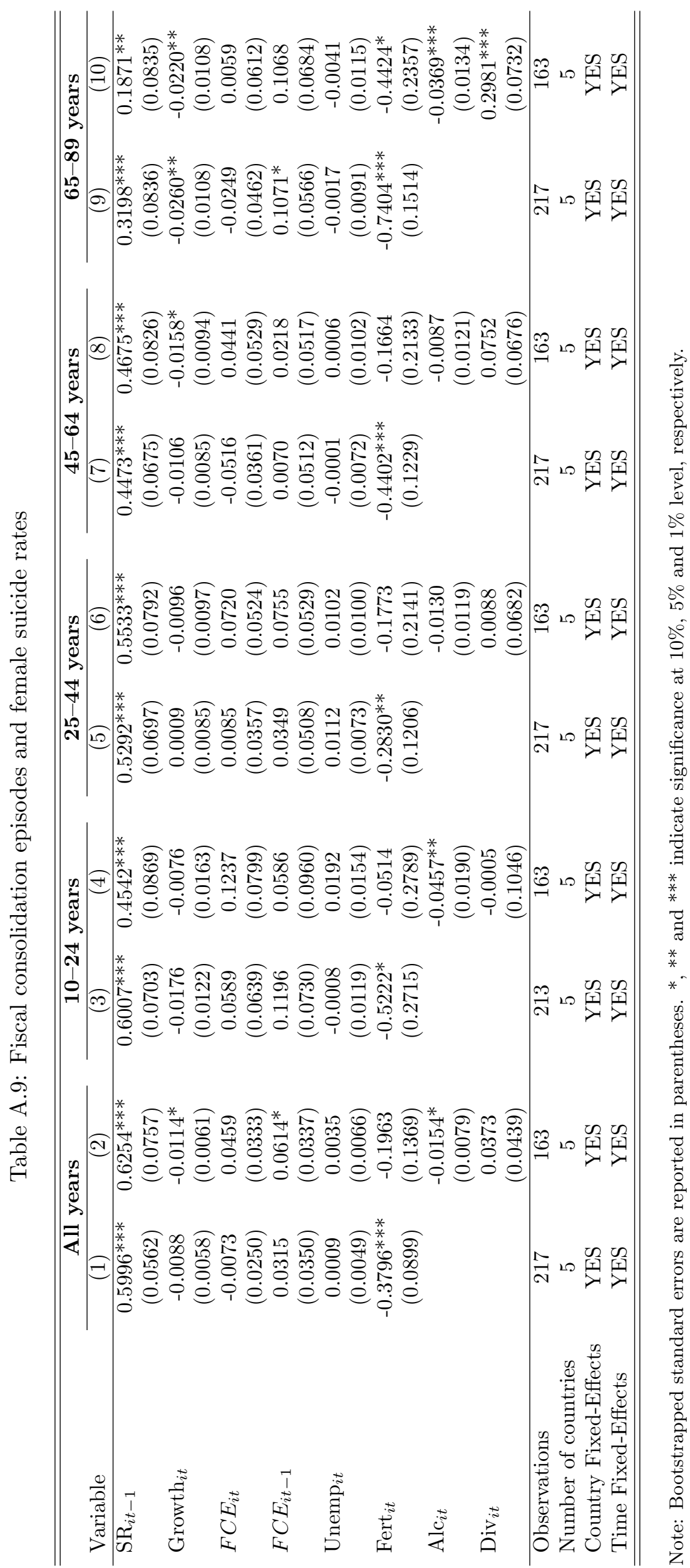




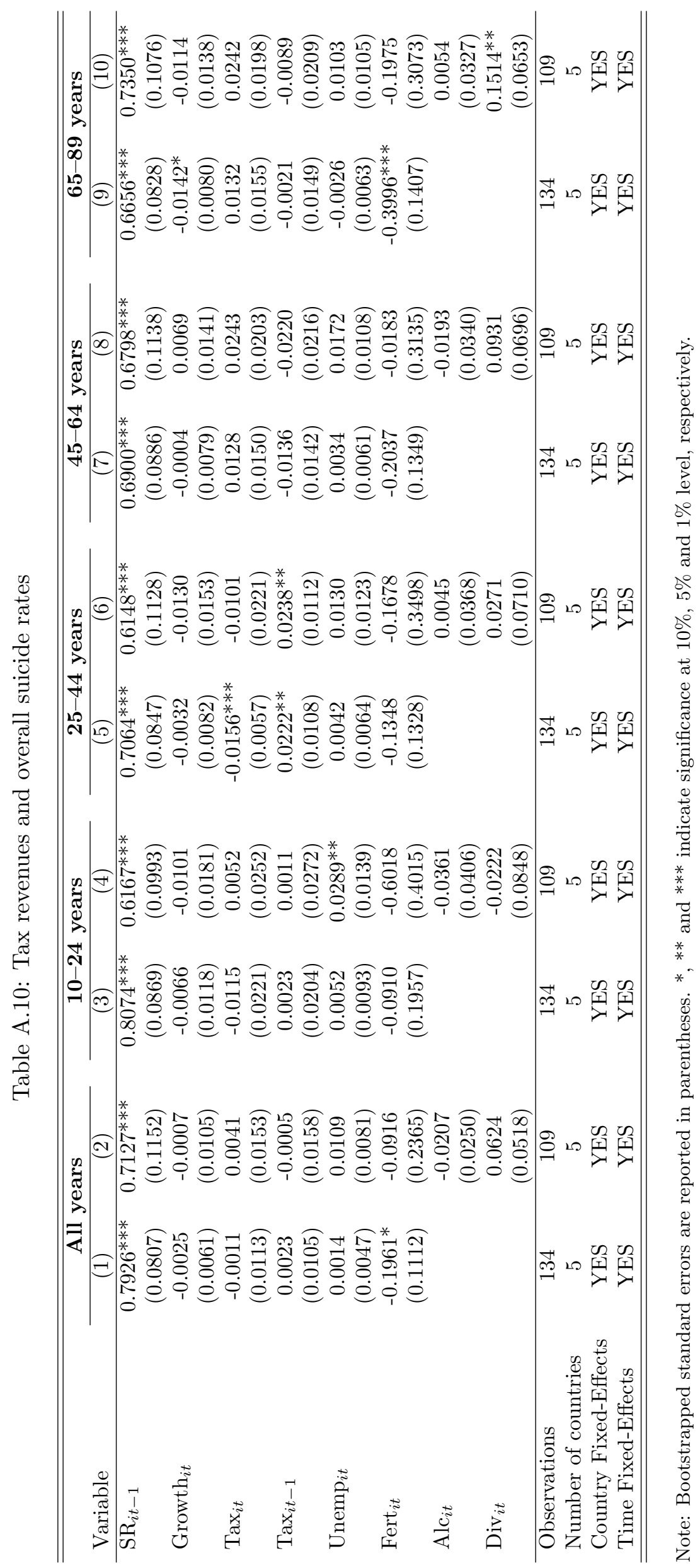




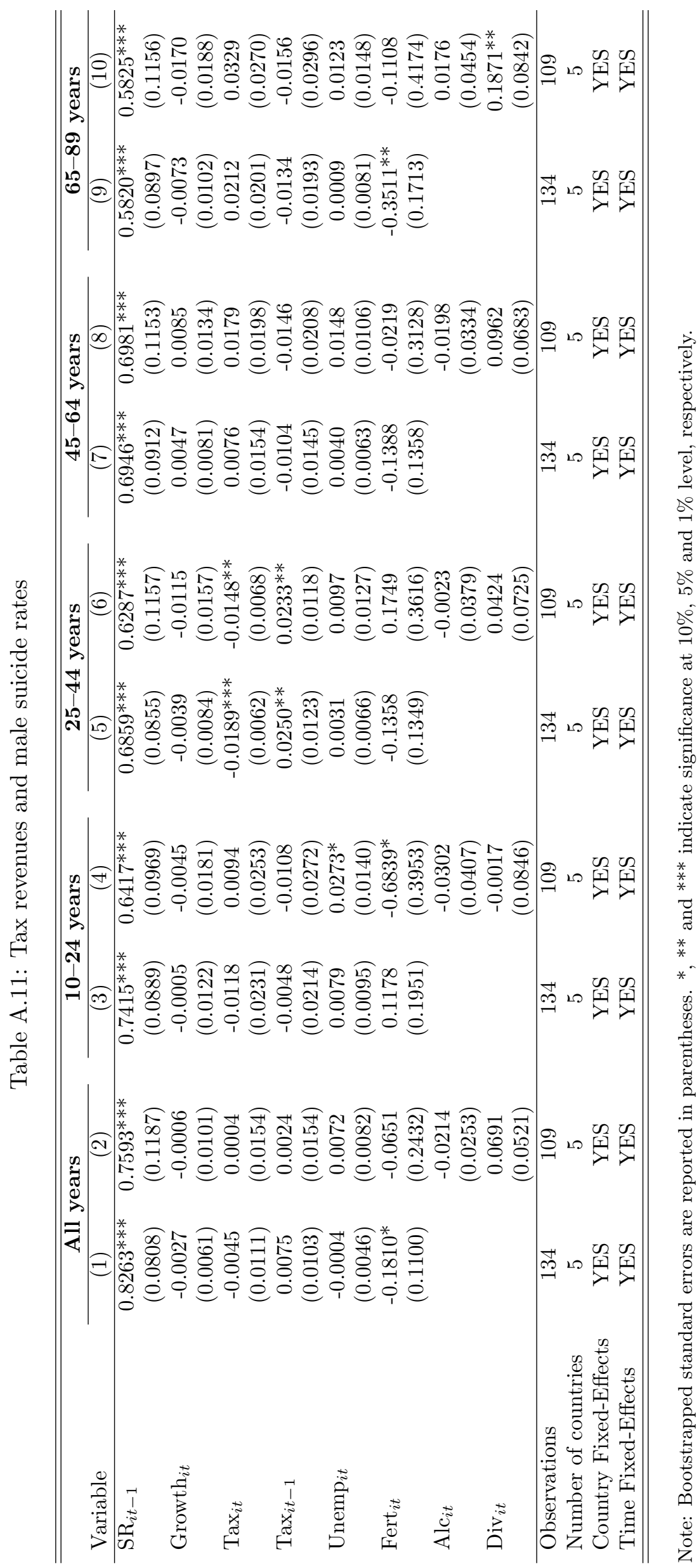




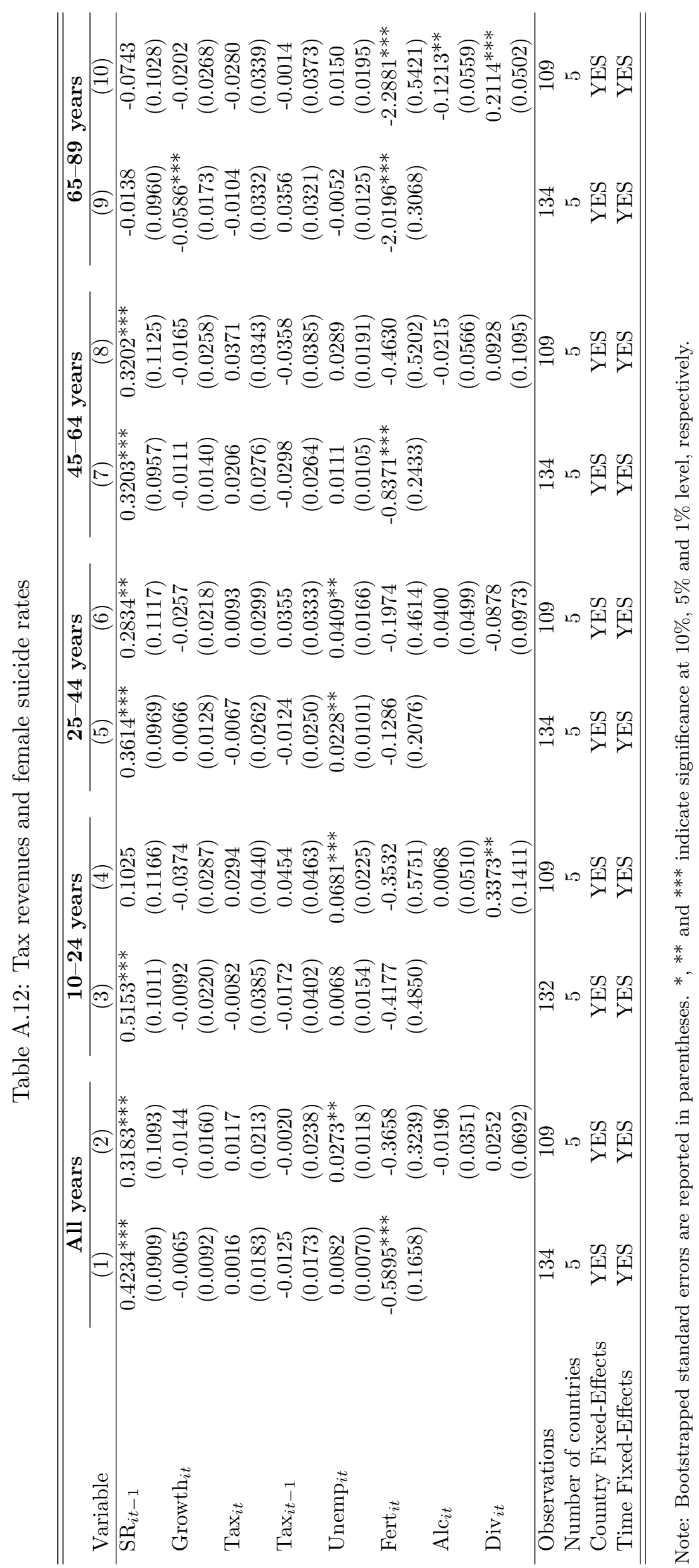




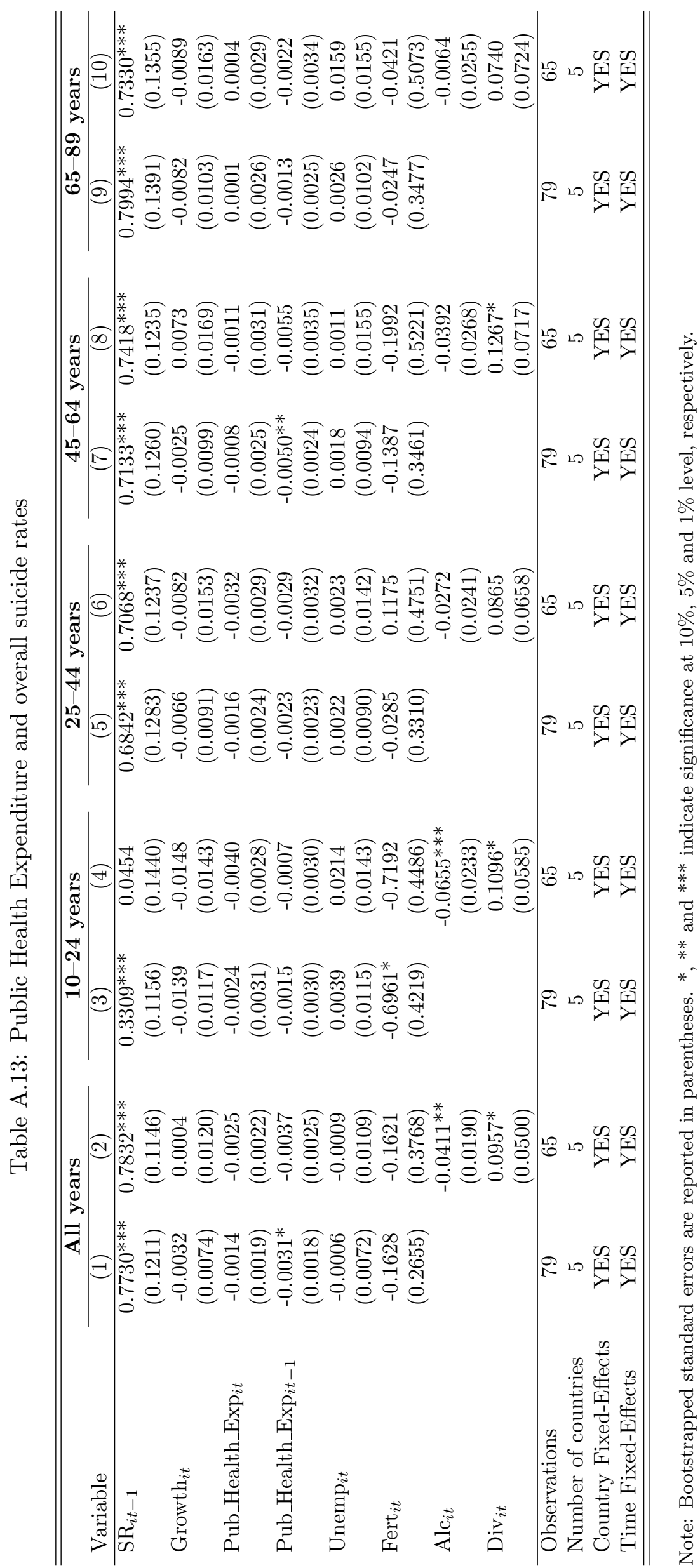




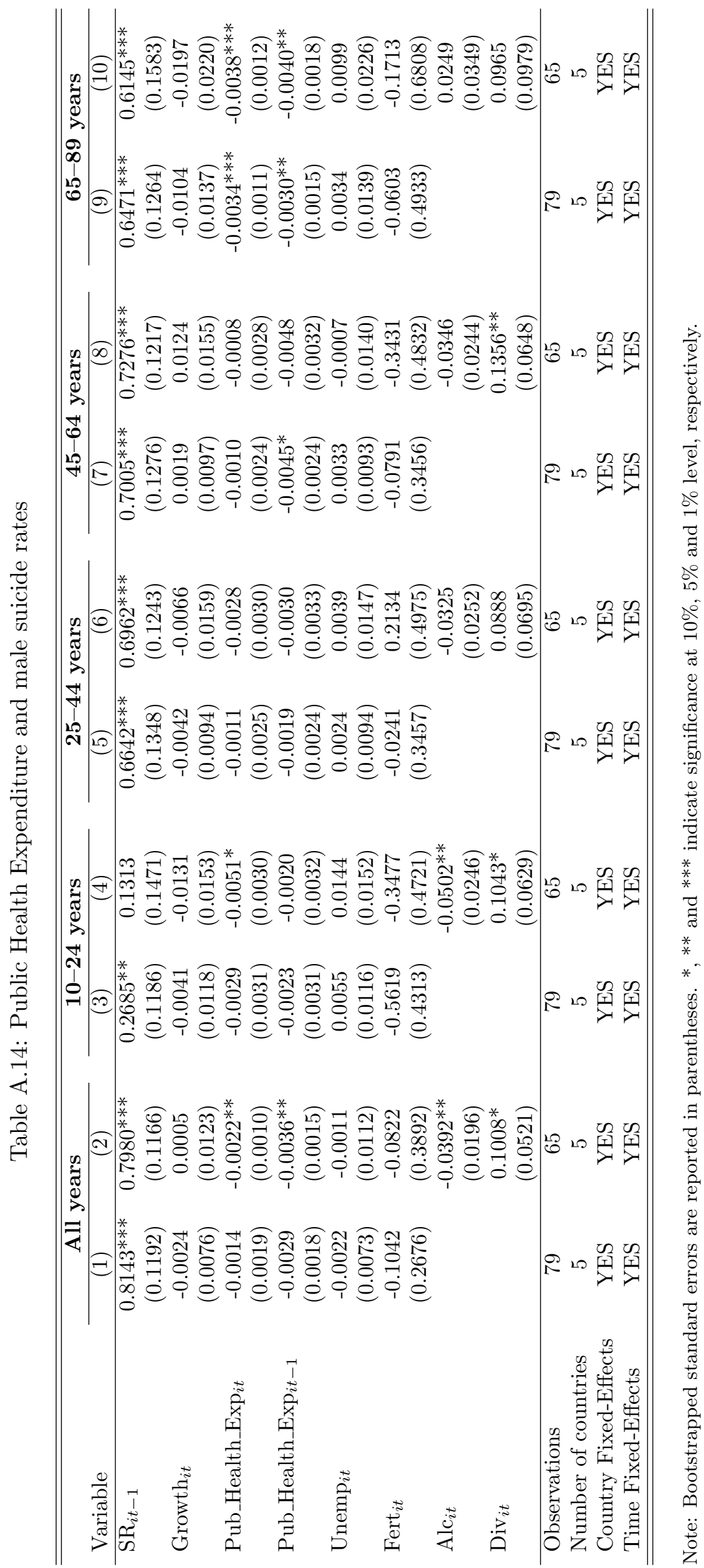




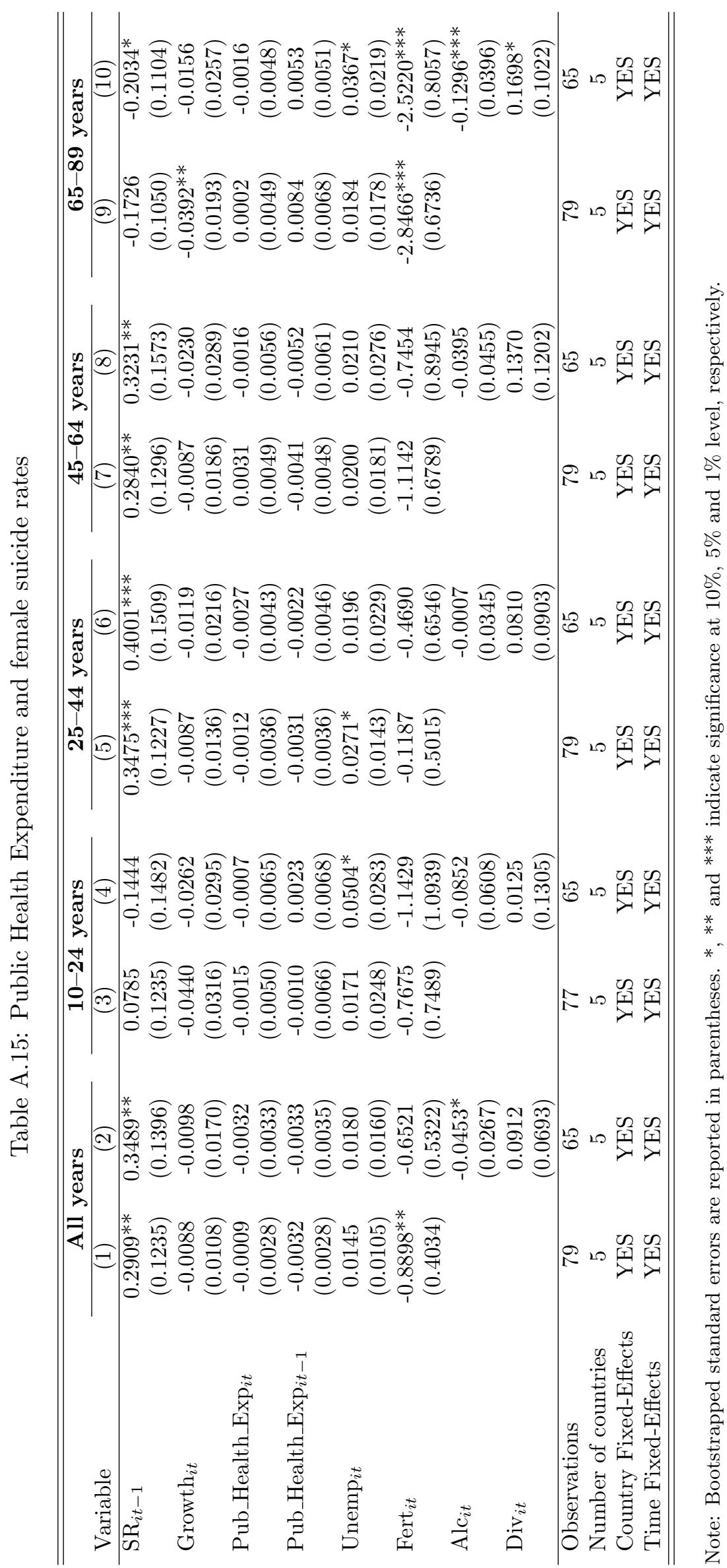

